\title{
Matrix Dissolution Techniques Applied to Extract and Quantify Precipitates from a Microalloyed Steel
}

\author{
JUNFANG LU, J. BARRY WISKEL, OLADIPO OMOTOSO, HANI HENEIN, \\ and DOUGLAS G. IVEY
}

\begin{abstract}
Microalloyed steels possess good strength and toughness, as well as excellent weldability; these attributes are necessary for oil and gas pipelines in northern climates. These properties are attributed in part to the presence of nanosized carbide and carbonitride precipitates. To understand the strengthening mechanisms and to optimize the strengthening effects, it is necessary to quantify the size distribution, volume fraction, and chemical speciation of these precipitates. However, characterization techniques suitable for quantifying fine precipitates are limited because of their fine sizes, wide particle size distributions, and low volume fractions. In this article, two matrix dissolution techniques have been developed to extract precipitates from a Grade100 (yield strength of $690 \mathrm{MPa}$ ) microalloyed steel. Relatively large volumes of material can be analyzed, and statistically significant quantities of precipitates of different sizes are collected. Transmission electron microscopy (TEM) and X-ray diffraction (XRD) are combined to analyze the chemical speciation of these precipitates. Rietveld refinement of XRD patterns is used to quantify fully the relative amounts of the precipitates. The size distribution of the nanosized precipitates is quantified using dark-field imaging in the TEM.
\end{abstract}

DOI: $10.1007 / \mathrm{s} 11661-010-0579-6$

(C) The Minerals, Metals \& Materials Society and ASM International 2010

\section{INTRODUCTION}

IT is known that the combination of microalloying additions, such as $\mathrm{Nb}, \mathrm{Ti}$, and $\mathrm{V}$, and thermomechanical-controlled processing (TMCP) can enhance the strength and ductility of so-called microalloyed steels. The improvement of mechanical properties results mainly from the refinement of ferrite grain size, precipitation, solute strengthening, and dislocation strengthening, ${ }^{[1-3]}$ of which the most important are grain refinement and precipitation strengthening. The first three can be expressed mathematically by Eq. 1. ${ }^{[3]}$

$$
\begin{aligned}
\sigma_{y}(\mathrm{MPa})= & \sigma_{i}+k_{y} d^{-1 / 2}+\left(\frac{10.8 v_{f}^{1 / 2}}{X}\right) \ln \left(\frac{X}{6.125 \times 10^{-4}}\right) \\
& +\sum k_{i} C_{i}
\end{aligned}
$$

where $\sigma_{y}$ is the yield stress, $\sigma_{i}$ is the friction stress of iron, $k_{y}$ is the strengthening coefficient for grain size, $d$ is the grain diameter in microns, $X$ is the size of precipitates in microns, $v_{f}$ is the volume fraction of a given precipitate size $(X), k_{i}$ is the strengthening coefficient for solute

JUNFANG LU, formerly PhD Graduate Student with the Department of Chemical and Materials Engineering, University of Alberta Edmonton, Alberta T6G 2V4, Canada, is now Engineer with Enbridge Pipelines Inc., Edmonton, Alberta T5J 3N7, Canada. J. BARRY WISKEL, Research Service Officer, and HANI HENEIN and DOUGLAS G. IVEY, Professors, are with the Department of Chemical and Materials Engineering, University of Alberta. Contact e-mail: doug.ivey@ualberta.ca OLADIPO OMOTOSO, Engineer, is with Suncor Energy Inc., Fort McMurray, Alberta T9H 3E3, Canada.

Manuscript submitted March 16, 2010.

Article published online December 23, 2010 strengthening of solute $i$, and $C_{i}$ is the concentration of solute $i$.

Equation 1 does not include a term for dislocation strengthening because cold deformation is not used commonly in hot-rolled or normalized microalloyed steels. $^{[3]}$

Different sized precipitates have been identified in microalloyed steels, and their precipitation is a sequential process because of solubility differences. Figure 1 shows a comparison of the solubility products (e.g., for $\mathrm{NbC}, K_{s}=[\mathrm{Nb}]_{\text {equilibium }}[\mathrm{C}]_{\text {equilibrium }}=10^{(\mathrm{A}-\mathrm{B} / T)}$, where $K_{S}$ is the solubility product, $T$ is temperature in Kelvin, and $\mathrm{A}$ and $\mathrm{B}$ are constants for a given system) for microalloyed carbides and nitrides. The solubility of precipitates establishes guidelines to identify different phases. It can be observed that $\mathrm{TiN}$ is the least soluble of the precipitates in austenite. TiN should precipitate out at higher temperatures during earlier processing stages and can be several microns in size. $\mathrm{NbC}$ has a much higher solubility and will precipitate out at lower temperatures during the subsequent processing stages with a much smaller size. The solubilities of VC and VN, especially VC, are much higher than those of the other alloying element carbides/nitrides in austenite and ferrite. Molybdenum carbide has a similar solubility to VC. ${ }^{[4]}$ Because of their high solubility, Mo and V carbides are expected to precipitate last and have the finest particle size. Therefore, precipitates can be classified into different groups according to precipitate size and their precipitation sequence.

Precipitates of different sizes contribute to each of these strengthening mechanisms in various ways. To maintain a fine austenite grain size prior to transformation, particles that precipitate in austenite or particles 


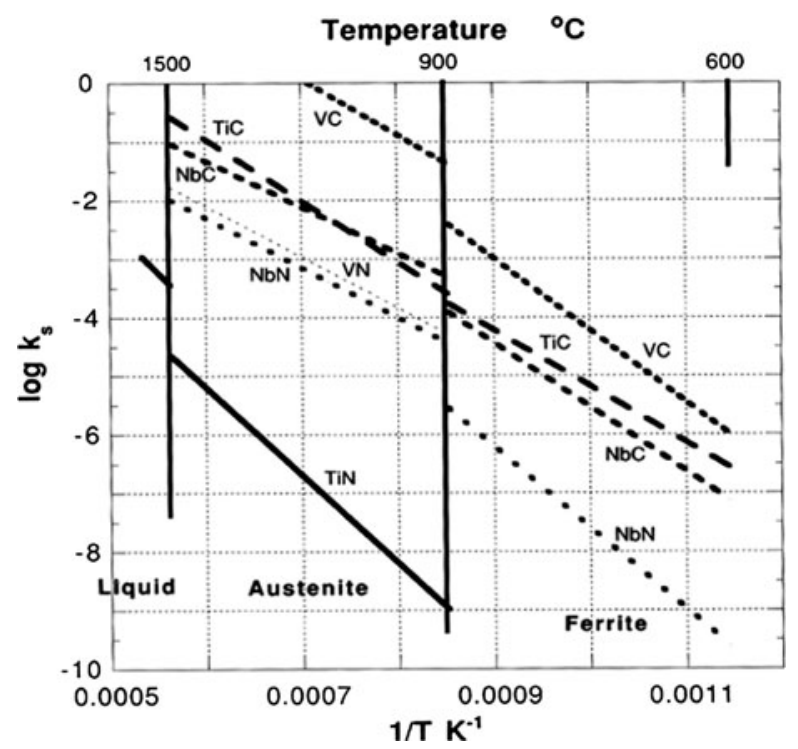

Fig. 1-Equilibrium solubility products for microalloyed carbides and nitrides in austenite and ferrite. ${ }^{[3]}$

that will precipitate during hot rolling are required. These precipitates, typically carbides, nitrides and/or carbonitrides of $\mathrm{Nb}$ and $\mathrm{Ti}$, are $>20 \mathrm{~nm}$ in size..$^{[5,6]}$ To produce precipitation strengthening, fine particles $(<20 \mathrm{~nm})$, especially those smaller than $5 \mathrm{~nm}$, are needed ${ }^{[7]}$ The finest nanoprecipitates are particularly important for precipitation strengthening.

Precipitation strengthening increases as the volume fraction of the precipitates increases and the precipitate size decreases. ${ }^{[1]}$ For a given volume fraction, refinement of particle size means a higher number density of precipitates, which means a higher number of interactions between precipitates and the dislocations in the ferrite matrix. Thus, a significant increase in yield stress can be produced. Therefore, refining precipitate size and increasing the volume fraction of the nanoprecipitates are important issues in the steel industry. However, quantitative determination of the volume fraction of the nanoprecipitates is challenging because of the small particle sizes, wide particle size distribution, and low volume fraction of precipitates. Another challenge is that $\mathrm{Ti}$ and $\mathrm{Nb}$ carbonitrides have the same crystal structure ( $\mathrm{NaCl}$-type), with similar lattice parameters. It is difficult to differentiate the precipitates solely on a chemical composition basis, making the problem more complicated.

Microscopic methods are used commonly for characterizing precipitates. Both optical microscopy and scanning electron microscopy (SEM) have limited resolution. Transmission electron microscopy (TEM) has superior imaging resolution and spatial resolution for energy dispersive X-ray (EDX) analysis. However, TEM analysis does have limitations because of the small specimens used. More recently, atomic force microscopy $(\mathrm{AFM})^{[8]}$ and atom probe field-ion microscopy (APFIM) have been used. $^{[9,10]}$ Similar to TEM, both AFM and APFIM can provide high resolution images. The advantages of AFM are its lower cost and ease of operation compared with TEM. APFIM is not as common but has advantages for nanoprecipitate investigation. High-resolution images are obtained by ionization of atoms from the specimen. ${ }^{[9]}$ The chemistry of the specimen can be determined accurately on a single particle as small as $1 \mathrm{~nm}$ in diameter. ${ }^{[9,10]}$ The disadvantage of APFIM is that the volume of material analyzed is much smaller than that in TEM. Sample preparation for APFIM is also complex and time consuming with only a small volume analyzed for each measurement. The sampling volume for AFM is also small.

With the previously discussed microscopic techniques, microstructural features of the steel matrix and precipitates have been examined. Qualitative or semiquantitative methods may have been sufficient in helping to increase steel strength to date; however, future improvements will need to be more quantitative. To improve steel mechanical properties effectively for the future development of new steels with higher strength, better toughness, and better weldability, such as X100, X120 (X refers to pipeline grade and 100/120 refers to the specified minimum yield strength in ksi), and beyond, a more quantitative understanding of the strengthening mechanisms is required. Based on the quantitative information, the relative importance and contribution of different strengthening mechanisms can be determined. However, this quantitative information is lacking and microscopic methods are not completely satisfactory for quantifying precipitate size, size distribution, and volume fraction of precipitates in steels because of the low volume of precipitates.

Based on previous work by the authors, matrix dissolution has been shown to be a successful technique to quantify precipitates from samples that are more representative of the steel strip. Relatively large volumes of material are analyzed, so that statistically significant quantities of precipitates of different sizes are collected. Matrix dissolution can be done either chemically or electrolytically to extract the carbonitrides. ${ }^{[1]}$

For electrolytic dissolution, it is possible to extract precipitates selectively by composition because of the different dissolution behavior of the various precipitates and the steel matrix. The ferrite matrix is dissolved at low anodic potentials, while precipitates are more noble and are dissolved at higher potentials. Some precipitates are more noble than others, thereby allowing selective extraction.

It is noted that matrix dissolution methods have been successful in extracting $\mathrm{Ti} / \mathrm{Nb} / \mathrm{Mo} / \mathrm{V}$ carbonitrides, both chemically and electrolytically, because of their insolubility in $\mathrm{HCl}$ acid and selected electrolytes. This technique may not be applicable to extract mixed $\mathrm{Fe}-\mathrm{Cr}-\mathrm{Mn}$ nanocarbides as reported by Chakraborty et al. ${ }^{[12,13]}$ They dissolve partially or are retained or embedded during refinement of the bainitic-ferrite sheaf. These mixed carbides may be soluble in $\mathrm{HCl}$ acid or an electrolyte.

In this article, both electrolytic and chemical dissolution methods are used and the results are compared. After the steel is dissolved, precipitates are separated from the solution by centrifuging. The extracted precipitates are specifically identified using TEM and X-ray diffraction (XRD) without interference from the matrix. 
Precipitate size is determined by TEM imaging and the chemistry is determined through TEM X-ray microanalysis. XRD is also used to provide valuable crystallographic information. Rietveld refinement of XRD patterns is used for refining precipitate structures and to obtain their relative abundance, making it possible to determine the volume fraction of precipitates in the steel.

\section{EXPERIMENTAL PROCEDURE}

Grade100 microalloyed steel, with a thickness of $8 \mathrm{~mm}$ and supplied by Evraz Inc. NA (Portland, OR), was used in this study. This is a high-strength, lowcarbon, low-alloy structural steel with a specified minimum yield strength of $100 \mathrm{ksi}$ (690 MPa). The Grade100 designation is the strength equivalent of Canadian Standards Association (CSA) Grade 690, which is the designation suggested by the CSA. This steel is produced through thermomechanical controlled processing (TMCP). The chemical composition of relevant elements is given in Table I. Manganese is one of the principal alloying agents in most steels. Both $\mathrm{Mn}$ and Mo provide solid-solution strengthening and suppress the austenite to ferrite phase transformation, resulting in the formation of lower transformation temperature products (such as acicular/bainitic ferrite) and finer precipitate dispersion. ${ }^{[14,15]}$ Manganese is also added in steels to combine with sulfur to form manganese sulfide $(\mathrm{MnS}) .{ }^{[16]}$ Small amounts of elements such as $\mathrm{Ti}, \mathrm{Nb}$, and $\mathrm{V}$ are added to this steel to increase the strength. Aluminum is not usually considered as a microalloying element. It is added primarily as a deoxidizer to the stee ${ }^{[17]}$ and works in conjunction with silicon.

Both electrolytic and chemical dissolution were used to dissolve the steel matrix and extract precipitates. Samples approximately 1.5 to $2 \mathrm{~cm}^{3}$ in volume, taken through the plate thickness, were used in both dissolution methods. An analytical balance with an accuracy of $0.1 \mathrm{mg}$ was used to measure the weight of the sample before dissolution and the weight of the extracted residues.

Various acids, such as $\mathrm{HCl}, \mathrm{H}_{2} \mathrm{SO}_{4}$, and $\mathrm{HNO}_{3}$, have been reported in the literature for extracting different types of particles. Only those phases stable in acids, such as silica, alumina, ${ }^{[18]}$ and several carbides and nitrides, have been extracted successfully. ASTM E194-90 ${ }^{[19]}$ is a standard test method to determine the acid-insoluble content of iron powders. In this standard, a dilute $\mathrm{HCl}$ solution is used. Insoluble matter, such as carbides, silica, insoluble silicates, alumina, clays, and other refractory materials, can be collected. Data are unavailable for the solubility of $\mathrm{TiC}, \mathrm{TiN}, \mathrm{VC}$, and $\mathrm{VN}$ in acids. However, it is reported that $\mathrm{NbC}$ and $\mathrm{NbN}$ are insoluble in any acid. ${ }^{[20]}$ Because of their similar crystal structures (all have $\mathrm{NaCl}$-type structures), it is reasonable to expect that these microalloyed carbides and nitrides will be insoluble in $\mathrm{HCl}$.

To define the appropriate conditions for electrolytic dissolution of the steel matrix, potentiodynamic curves for the Grade100 steel and several binary carbides and nitrides were obtained using a Gamry Potentiostat/ Galvanostat system (Gamry PC4/750, Gamry Instruments, Warminster, PA). The electrolyte employed was 10 pct acetylacetone (AA) solution, ${ }^{[21]}$ which consists of 10 pct acetylacetone, 1 pct tetramethylammonium chloride and methanol. During each potentiodynamic scan, the steel sample, pure carbide, or pure nitride acted as the anode, with platinum sheet as the cathode. Using the same Gamry system, a static potential $(300 \mathrm{mV}$ vs saturated calomel electrode [SCE]) was applied during electrolytic dissolution to dissolve the matrix and to leave behind the precipitates. For chemical dissolution, an $\mathrm{HCl}$ acid solution (1:1 mixture by volume of $\mathrm{HCl}$ acid, with a specific gravity 1.19 , and distilled water) was used at $338 \mathrm{~K}$ to $343 \mathrm{~K}\left(65^{\circ} \mathrm{C}\right.$ to $\left.70^{\circ} \mathrm{C}\right)$. Henceforth, dissolution using 10 pet AA will be referred to as electrolytic dissolution, and dissolution using the $\mathrm{HCl}$ solution will be referred to as chemical dissolution.

After the steel matrix was dissolved, a Sorvall RC-6 super speed centrifuge (Mandel, Guelph, ON, Canada) made by Mandel, was used to separate solid particles from the solution by rotating the material rapidly at up to $40,000 \mathrm{RCF}$ (relative centrifugal force) at $277 \mathrm{~K}$ $\left(4{ }^{\circ} \mathrm{C}\right)$. The centrifuging process was repeated several times to clean the precipitates. Inductively coupled plasma spectroscopy (ICP), with a Perkin Elmer Elan 6000 ICP-MS (Perkin Elmer, Waltham, MA), was used to analyze the concentration of the elements in the supernatant extracted by chemical dissolution, as a means of performing a mass balance. Calibration was done using four calibration levels (four-point calibration curve) for each element. The solution to be analyzed was diluted to keep the analyte concentration within the linear working range.

For phase identification, diffraction data were collected with a Bruker D8 Advance X-ray diffractometer (Bruker AXS Inc., Madison, WI), equipped with a Co X-ray source and a VANTEC-1 linear detector. Two techniques were used for TEM sample preparation: one using precipitates extracted during matrix dissolution and the other using precipitates produced from carbon extraction replicas. For the first case, a fraction of the precipitates extracted using electrolytic or chemical dissolution was dispersed in ethanol. A drop of the suspension was deposited on a carbon-coated, 300-mesh $\mathrm{Cu}$ grid, and the solvent was allowed to evaporate, leaving behind the particles. These samples were used to identify specific types of precipitates. The compositions of the precipitates were determined by EDX analysis in

Table I. Chemical Composition of Grade100 Microalloyed Steel (Weight Percent)

\begin{tabular}{lccccccccccr}
\hline Element & $\mathrm{C}$ & $\mathrm{Mn}$ & $\mathrm{Si}$ & $\mathrm{N}$ & $\mathrm{Cu}+\mathrm{Ni}+\mathrm{Cr}$ & $\mathrm{Mo}$ & $\mathrm{Nb}$ & $\mathrm{Ti}$ & $\mathrm{V}$ & $\mathrm{Al}$ & $\mathrm{Ca}$ \\
\hline Wt pct & 0.080 & 1.800 & 0.244 & 0.011 & 0.877 & 0.301 & 0.094 & 0.06 & 0.047 & 0.05 & 0.005 \\
\hline
\end{tabular}


the TEM, where a standard-less approach was used. For the second case, a thin carbon film was evaporated onto the surface of a polished/etched steel metallographic sample. TEM samples were taken from regions through the plate thickness, although the midthickness and surface regions were avoided. The carbon film was stripped from the surface and extracted precipitates from the surface region of the ferrite matrix. Dark-field (DF) imaging was used to characterize the size distribution of nanoprecipitates extracted from the ferrite matrix onto carbon replicas supported on $\mathrm{Cu}$ grids. The compositions of the precipitates in the carbon extraction replicas were determined by EDX analysis in the TEM as well. The first technique (matrix dissolution) produced many more particles than the second technique (carbon extraction replicas), which will be discussed subsequently. The samples were examined in a JEOL 2010 TEM (JEOL Ltd., Tokyo, Japan) equipped with an EDX detector operating at $200 \mathrm{kV}$.

TOPAS Academic software (Bruker AXS Inc., Madison, WI) was used for Rietveld analysis of the precipitate structures and to determine their composition. The technique uses a nonlinear least squares method to refine instrument and structural parameters contributing to a calculated diffraction pattern until a good match is generated. ${ }^{[22,23]}$ Given that precipitates have similar structures and lattice parameters, the element occupancies were fixed based on the precipitate chemical composition obtained by EDX analysis. The scale factor and lattice parameters (with tight restraints) were refined to reduce strong parameter correlations. The phase fractions were derived from Eq. [2]. ${ }^{[24]}$

$$
w_{a}=\frac{S F_{a}(M Z V)}{\sum_{j} S F_{j}(M Z V)_{j}}
$$

where $w_{a}$ is the relative weight fraction of phase $a$ in a mixture of $j$ phases, $S F$ is a refined scale factor and is proportional to the number of unit cells of phase $a$ in the specimen, $M$ is the mass of the molecular formula, $Z$ is the number of formula units per unit cell, and $V$ is the volume of the unit cell.

\section{RESULTS}

\section{A. Polarization Behavior of Grade100 Steel and Binary Precipitate Materials}

Polarization curves using electrolytic dissolution for the Grade100 steel (ferrite matrix) and several binary carbides and nitrides are shown in Figure 2. Clearly, the steel matrix is the most soluble followed by $\mathrm{TiN}$, TiC, and then $\mathrm{NbC}$ and $\mathrm{NbN}$. The matrix can be dissolved selectively, at potentials $<1000 \mathrm{mV}$ vs SCE. In addition, TiN (the largest of the precipitates in the steel) is electrolytically dissolved preferentially relative to the other carbides/nitrides at potentials $<1500 \mathrm{mV}$ vs SCE, leaving behind the other compounds. If a high potential, i.e., $1500 \mathrm{mV}$, is supplied within the current range of the equipment, then smaller precipitates can be extracted from the ferrite matrix and TiN selectively dissolved.

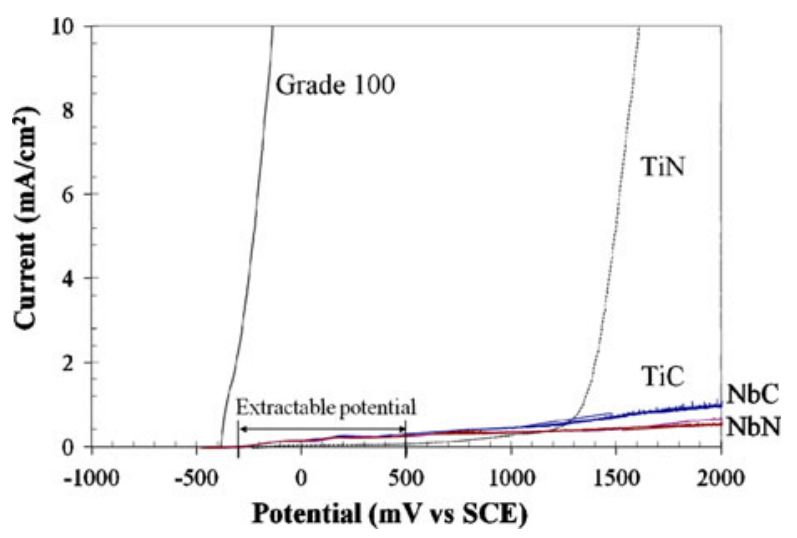

Fig. 2-Polarization curves for Grade100 steel and binary precipitates in the 10 pct AA solution.

Table II. Experimental Extraction Yield of Residue from Two Dissolution Methods

\begin{tabular}{lcc}
\hline Dissolution method & $\begin{array}{c}\text { Electrolytic } \\
(10 \text { pct AA })\end{array}$ & $\begin{array}{c}\text { Chemical } \\
(\mathrm{HCl})\end{array}$ \\
\hline $\begin{array}{c}\text { Experimental extraction } \\
\text { yield (wt pct) }\end{array}$ & $0.361 \mathrm{pct}$ & $0.792 \mathrm{pct}$ \\
\hline
\end{tabular}

However, this has been shown to be impractical for the Gamry system used in this work. If a significant amount of precipitates is to be extracted, then the total surface area of the steel to be dissolved needs to be several $\mathrm{cm}^{2}$, which means the current will exceed the current range of the system. This issue could be overcome by the use of several power supplies and smaller specimens.

\section{B. Mass Balance of the Supernatant and the Extracted Residue}

The experimental extraction yield, i.e., total wt pct of the residue relative to the amount of steel being dissolved, by two dissolution methods is shown in Table II.

For $\mathrm{HCl}$ dissolution, ICP analysis was performed on the centrifuged solution after the precipitates had been extracted from the $\mathrm{HCl}$ solution. By comparing the chemical composition of the steel with the ICP analysis of the solution, the amount of each element extracted from the steel as part of the residue was obtained, as shown in Table III. Most of the $\mathrm{Si}$ in the steel was present in the residue as $\mathrm{SiO}_{2}$, which was verified by the following TEM analysis. Most of the $\mathrm{Nb}$ in the steel was in precipitate form. There are lower yields for $\mathrm{Ti}, \mathrm{Mo}$, and $\mathrm{V}$, especially for Mo and V, which means that most of the Mo and V were dissolved in solid solution in the ferrite matrix.

\section{Preliminary XRD Analysis of the Extracted Residues}

Figure 3 shows XRD patterns for residues extracted from the Grade100 steel; samples were obtained through electrolytic and chemical dissolution, respectively. The main difference for the two matrix dissolution techniques is the presence of a broad peak for chemical 
Table III. ICP Analysis of the Supernatant After Chemical Dissolution

\begin{tabular}{|c|c|c|c|c|c|}
\hline Grade100 & $\mathrm{Si}$ & $\mathrm{Nb}$ & $\mathrm{Ti}$ & Mo & $\mathrm{V}$ \\
\hline Steel chemistry (wt pct) & 0.244 & 0.094 & 0.06 & 0.301 & 0.047 \\
\hline Supernatant chemistry (wt pct) & 0.021 & 0.003 & 0.014 & 0.257 & 0.045 \\
\hline Extraction yield of precipitates & $91.6 \mathrm{pct}$ & $97.2 \mathrm{pct}$ & $76.3 \mathrm{pct}$ & $14.5 \mathrm{pct}$ & $5.0 \mathrm{pct}$ \\
\hline
\end{tabular}

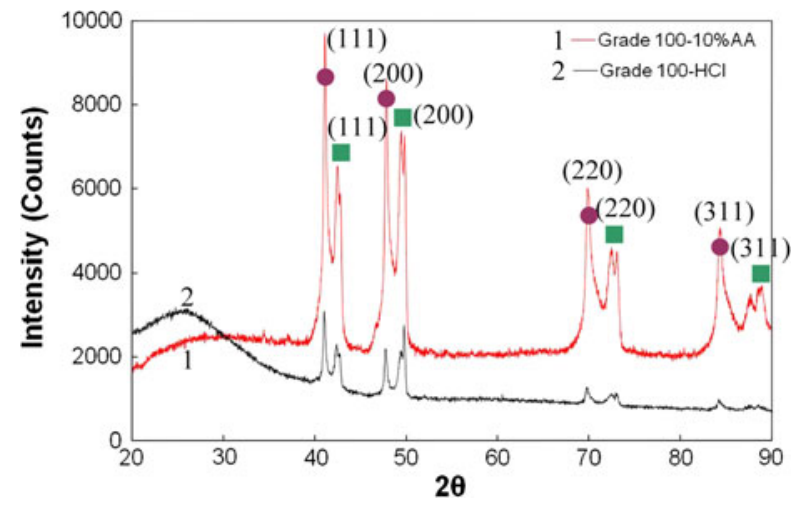

Fig. 3-XRD patterns for residues extracted from Grade100 steel by electrolytic (10 pet AA) and chemical dissolution $(\mathrm{HCl})$.

dissolution between the $2 \theta$ angles of $20 \mathrm{deg}$ and $30 \mathrm{deg}$, which is because of the presence of an amorphous phase, identified by TEM analysis as silica. The silica phase is discussed in more detail in subsequent sections. The broad peak was not found in the XRD pattern for residues extracted by electrolytic dissolution, which is advantageous for profile fitting in Rietveld analysis. The absence of the broad amorphous peak in the sample allows for a better signal-to-noise ratio and peak resolution in the diffraction pattern, making Rietveld refinement less error prone. However, on the negative side, electrolytic dissolution is much more time consuming than chemical dissolution.

A preliminary analysis of the diffraction patterns shows the apparent presence of two crystalline phases with similar structures; it will be shown subsequently that more phases are actually present. One set of peaks (indicated by circles in Figure 3) seems to represent NbC-based precipitates (larger $d$ spacings), and the other set (squares in Figure 3) corresponds to TiNbased precipitates. Both types of precipitates have a $\mathrm{NaCl}$-type (face-centered cubic [fcc]) structure with an Fm-3m space group. There are intensity differences, particularly for the $\{111\}$ and $\{200\}$ peaks among the two patterns, which is because of sample orientation effects during XRD measurements.

Because the crystal structure ( $\mathrm{NaCl}$-type) and lattice parameters of the precipitates are similar and the lattice parameters vary with composition, it is difficult to differentiate between the various carbides, nitrides, and carbonitrides.

\section{TEM Analysis of Nanoprecipitates Extracted by Carbon Replicas}

Precipitates, especially the nanoprecipitates, can be extracted via carbon replicas. Because of the difficulty in analyzing fine precipitates, the size distribution of the nanoprecipitates was investigated using dark-field imaging. Figure 4(a) shows an example of a TEM bright-field (BF) image from a Grade100 carbon replica. The inset shows the corresponding selected area diffraction (SAD) pattern from the field of view. Several intermittent rings are visible and correspond to fine precipitates with a $\mathrm{NaCl}$-type crystal structure. Figure 4(b) shows a DF image, taken using part of the $\{111\}$ and $\{200\}$ diffraction rings. Several DF images were taken by varying the position of the objective aperture around the diffraction rings, so that all particles in the field of view were selected. Image processing software (ImageTool) was used to analyze the DF images and to quantify the size distribution of the nanosized precipitates. Figure 4(c) shows an EDX spectrum from some of the nanosized precipitates. They are $\mathrm{Nb} / \mathrm{Mo}$-rich with smaller amounts $\mathrm{Ti}$ and $\mathrm{V}$. Although $\mathrm{C}$ is present in the precipitates, the large $\mathrm{C}$ peak arises primarily from the carbon film in the replica. The $\mathrm{Cu}$ peaks are an artifact arising from the $\mathrm{Cu}$ support grid and the small $\mathrm{Fe}$ peak is residual matrix material. The relative frequency $v s$ diameter of nanoprecipitates in the Grade100 steel is shown in Figure 4(d). More than 2000 nanoprecipitates (mainly $\leq 10 \mathrm{~nm}$ ) were counted for the size distribution and chemistry analysis. The relative frequency $(n / N)$ is defined as the ratio of the number of particles $(n)$ within a given size range to the total number of particles counted in that region $(N)$. The largest number of precipitates is in the 3 to $5 \mathrm{~nm}$ size range. From Figure 4(d), the diameter with the largest number distribution is approximately $4.5 \mathrm{~nm}$.

\section{E. Characterization of Precipitates Extracted by Matrix Dissolution}

The size and chemistry of the precipitates extracted by matrix dissolution were characterized by TEM imaging and EDX microanalysis. Compared with carbon extraction replica methods, approximately 10,000 times more precipitates are extracted by matrix dissolution, making phase quantification possible. This estimation is based on the thickness of steel-contributing precipitates to the carbon replicas and the amount of steel dissolved during matrix dissolution.

\section{Large and intermediate-size precipitates extracted} by chemical and electrolytic dissolution

Figure 5 shows a TEM BF image of a large cuboidal precipitate approximately $3 \mu \mathrm{m}$ in size. It was extracted by chemical dissolution. EDX analysis indicates that it is Ti-rich with a small amount of $\mathrm{Nb}$. It is likely that the large cuboidal precipitates are formed at high temperature, in the liquid, or during or soon after casting. 


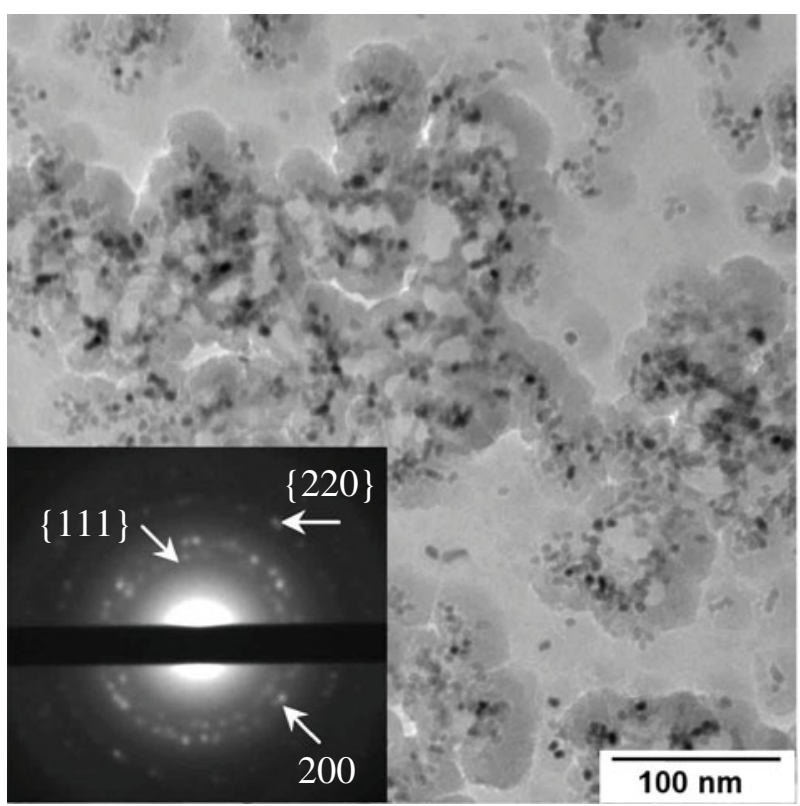

(a)

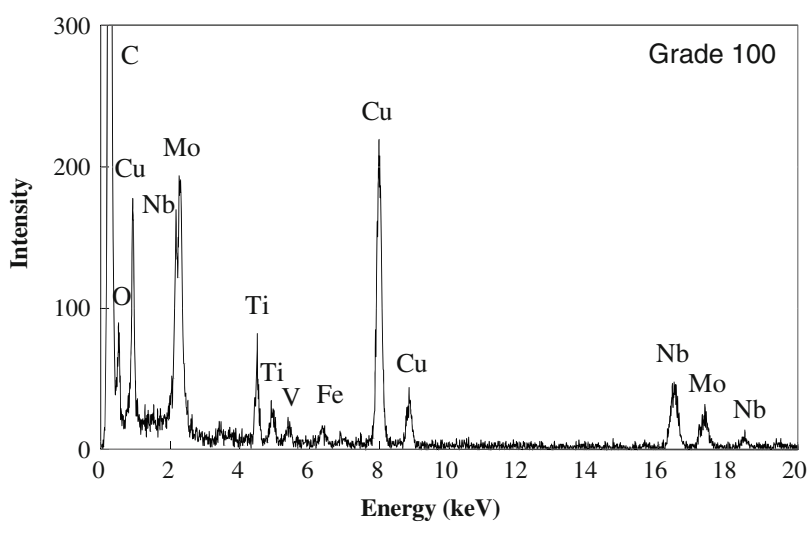

(c)

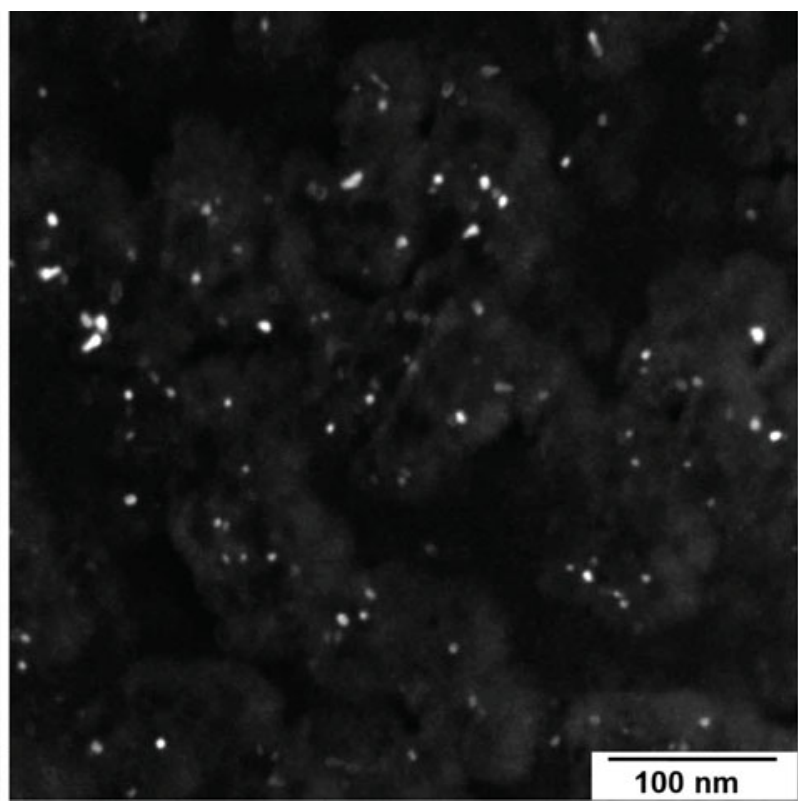

(b)

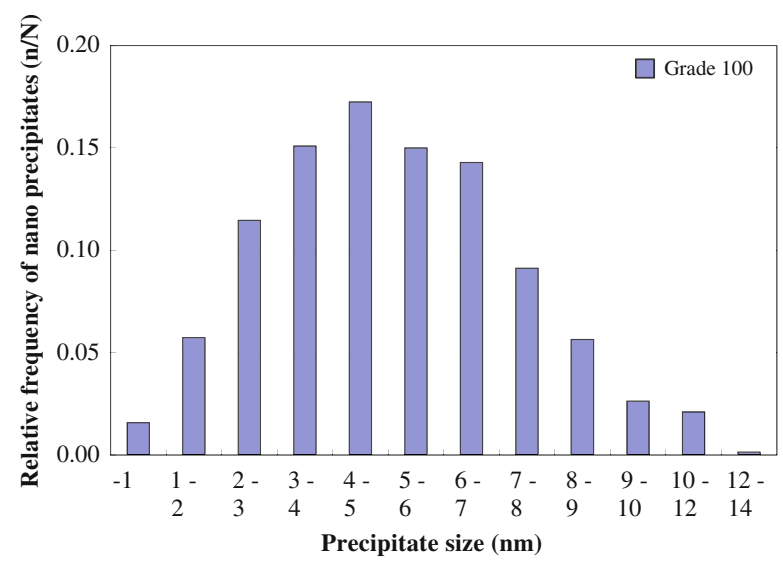

(d)

Fig. 4 - (a) TEM BF image of nanoprecipitates extracted via carbon replicas. (b) TEM DF image of same region as shown in (a). (c) EDX spectrum from several nanoprecipitates. (d) Size distribution of nanoprecipitates.

They are too large to affect austenite grain size refinement during reheating. As such, it is desirable to avoid the formation of this type of precipitate.

Some epitaxially nucleated precipitates were extracted by both chemical and electrolytic dissolution. Figure 6 shows an example of a TEM BF image, EDX spectra, and SAD patterns from the Nb-rich precipitates attached to a Ti-rich precipitate, extracted by electrolytic dissolution. Because TiN has a lower solubility in $\mathrm{Fe}$ (either austenite or ferrite) than $\mathrm{NbC}, \mathrm{NbN}$, or $\mathrm{Nb}$ carbonitrides, it precipitates first in the steel on cooling and can act as nucleation sites for $\mathrm{Nb}$-rich precipitates as shown in Figure 6(a). Figures 6(b) and (c) show EDX spectra of the Ti-rich precipitate and one of the $\mathrm{Nb}$-rich precipitates in Figure 6(a). The source of the $\mathrm{C}, \mathrm{Cu}$, and $\mathrm{Fe}$ is the same as explained previously. An SAD pattern, with a zone axis close to [114], of the overlapping Ti-rich precipitate and $\mathrm{Nb}$-rich precipitate is shown in Figure 6(d). Figure 6(e) shows an SAD pattern of the
Ti-rich precipitate in Figure 6(a). The (262) reflection in Figure 6(d), which is indicated by an arrow, shows spot splitting caused by the slightly different lattice parameters for the two phases. The Ti-rich precipitates have a smaller lattice parameter than the Nb-rich precipitates. Therefore, spots A (smaller $d$ spacing) and B (larger $d$ spacing) in Figure 6(d) come from the Ti-rich and $\mathrm{Nb}-$ rich precipitates, respectively. The coarse, Ti-rich nitrides (cuboidal in shape) are formed during or soon after casting (as discussed previously), whereas the $\mathrm{Nb}$ rich precipitates form in the austenite phase with many growing epitaxially on Ti-rich precipitates. This phenomenon has been reported previously. Epitaxial growth is favored as the decrease in interfacial energy between the $\mathrm{Nb}$-rich precipitate and preexisting $\mathrm{TiN}$ precipitate is much larger than the increase in strain energy from the small lattice misfit $(\sim 2 \mathrm{pct}) .^{[4,25]}$

Another type of intermediate-size precipitate $(\sim 100 \mathrm{~nm}$ in size $)$ was observed in the Grade100 steel. 


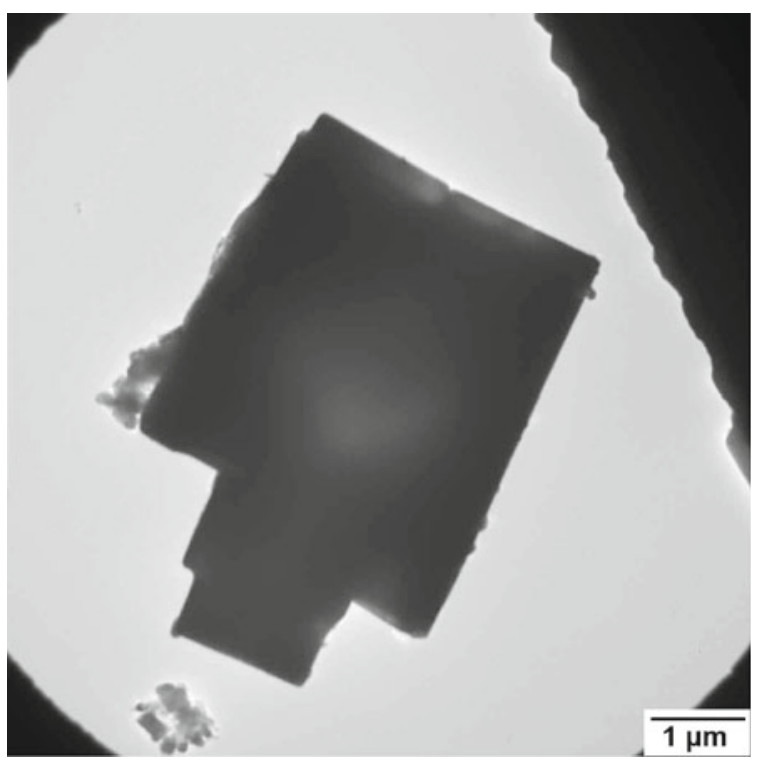

(a)

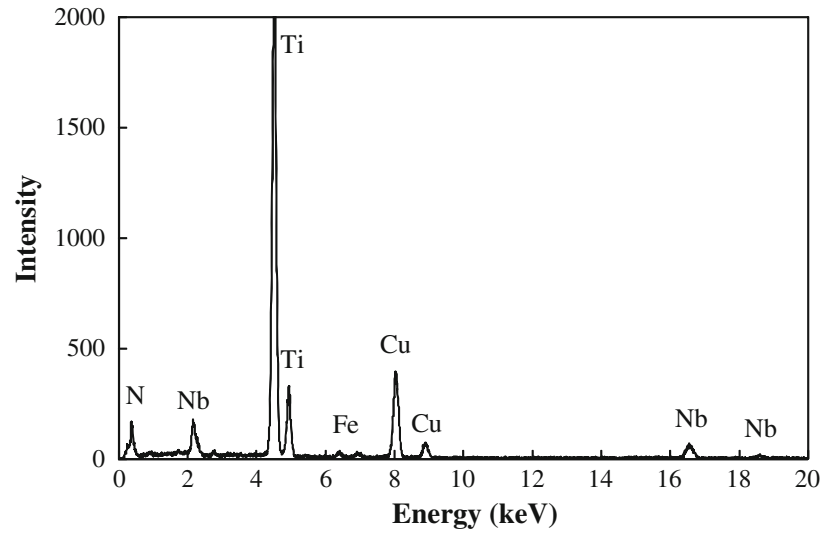

(b)

Fig. 5-(a) TEM BF image of a large Ti-rich precipitate extracted by chemical dissolution using HCl. (b) EDX spectrum from the Ti-rich precipitate in $(a)$.

A representative BF image and an EDX spectrum are shown in Figure 7. EDX analysis indicates that it has similar amounts of $\mathrm{Ti}$ and $\mathrm{Nb}(\sim 50$ at. pet $\mathrm{Ti}$ and $\sim 50$ at. pet $\mathrm{Nb}$ ).

\section{TEM analysis of nanoprecipitates extracted}

\section{by matrix dissolution}

Figure 8 shows TEM images of extracted nanoprecipitates from the Grade100 steel by chemical dissolution. The finest precipitates extracted are less than $5 \mathrm{~nm}$ in size (Figure 8(b)). EDX analysis (Figure 8(c)) reveals that the particles are Nb- and Mo-rich, and they contain small amounts of $\mathrm{Ti}$ and $\mathrm{V}$, which confirms the results from the extraction replicas in the previous section. An amorphous Si-O phase (Figures 8(d) and (e)), viewed as spherical particles in Figure 8(a), was also present in the residue. The $\mathrm{Si}$ and $\mathrm{O}$ peaks in Figure 8(c) are from this $\mathrm{Si}-\mathrm{O}$ phase. This finding is consistent with the ICP analysis of the supernatant where most of the $\mathrm{Si}$ in the steel matrix was present in the residue. The amorphous $\mathrm{Si}-\mathrm{O}$ phase is expected to be $\mathrm{SiO}_{2}$, which was confirmed by comparing the $d$ spacing of the broad ring in Figure 8(e) with the most intense peak for cristobalite. To determine whether the source of $\mathrm{O}$ for the $\mathrm{Si}-\mathrm{O}$ particles in the residue was the $\mathrm{HCl}$ solution (i.e., dissolved oxygen), $\mathrm{N}_{2}$ was bubbled through the solution both prior to and during dissolution. $\mathrm{SiO}_{2}$ was still extracted in the residue in the same quantities after $\mathrm{N}_{2}$ treatment, so the source of $\mathrm{O}$ was likely oxide/silicate inclusions in the steel or dissolved $\mathrm{Si}$ in the ferrite matrix. During steel dissolution, the inclusions are dissolved in the $\mathrm{HCl}$ solution and the dissolved $\mathrm{Si}$ combines with dissolved $\mathrm{O}$ to precipitate out as the amorphous Si-O phase.

Nanoprecipitates $(\leq 10 \mathrm{~nm})$ can also be extracted by electrolytic dissolution. Figure 9 shows a TEM BF image and EDX spectrum of electrolytically extracted nanoprecipitates from the Grade100 steel. The nanoprecipitates, as expected, are similar in size and in chemistry compared with those extracted by chemical dissolution. EDX analysis shows that they are $\mathrm{Nb} / \mathrm{Mo}-$ rich with some $\mathrm{Ti}$ and $\mathrm{V}$. The $\mathrm{Si}$ peak is much less intense than that for the chemically extracted residues, because of reduced formation of the amorphous Si-O phase. This is a clear advantage of electrolytic dissolution. However, on the negative side, electrolytic dissolution is more time consuming. The precipitate yield was only approximately 10 pct of that generated by chemical dissolution for the same amount of extraction time. As such, the sample size for XRD analysis was significantly smaller for electrolytically extracted residues. In addition, it takes approximately three times longer to clean the electrolytically extracted residues.

From the preceding TEM imaging and EDX microanalysis, different size precipitates with various compositions can be extracted successfully by matrix dissolution using both chemical and electrolytic methods. The precipitates extracted by the different methods are similar in size and composition and can be categorized into five groups accordingly. Precipitate grouping is similar to that observed by other researchers for the same grade of steel. ${ }^{[6]}$ More than 70 precipitates greater than $10 \mathrm{~nm}$ in diameter and more than 2000 nanoprecipitates less than or equal to $10 \mathrm{~nm}$ in diameter were characterized. Table IV summarizes the precipitate information from the Grade100 steel. The transition element compositions represent average values measured for precipitates of a particular size. The $\mathrm{C}$ and $\mathrm{N}$ compositions could not be quantified by EDX analysis, because of the presence of the carbon film and overlap of the N K peak with the Ti L peaks. The large Ti-rich 


\section{2: Nb-rich}

\section{1: Ti-rich}

\section{3: Nb-rich}

$2 \overline{\mathrm{n}} \mathrm{m}$

(a)

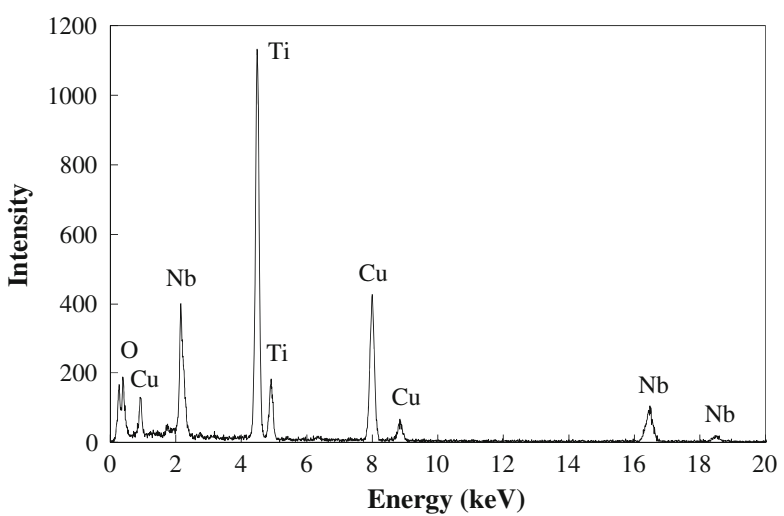

(b)

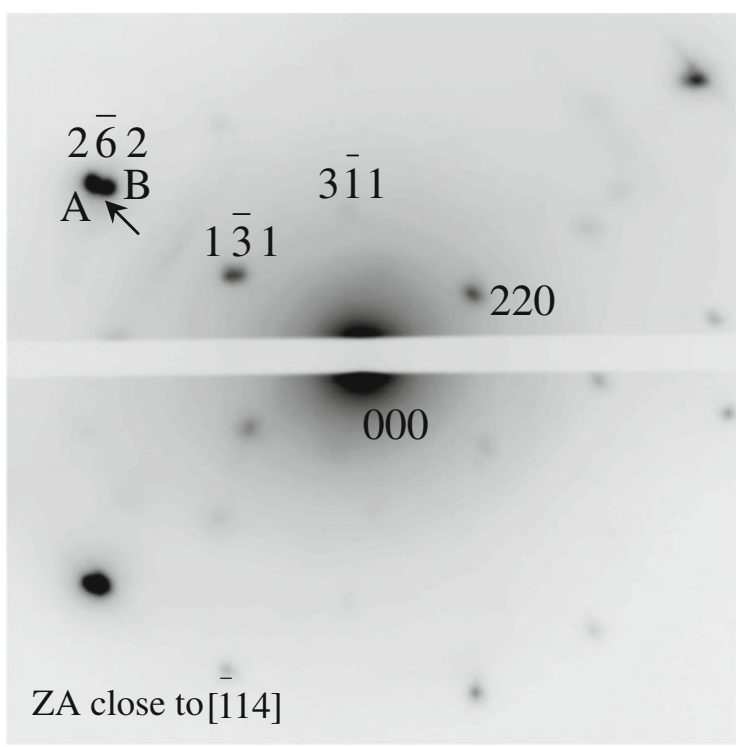

(d)

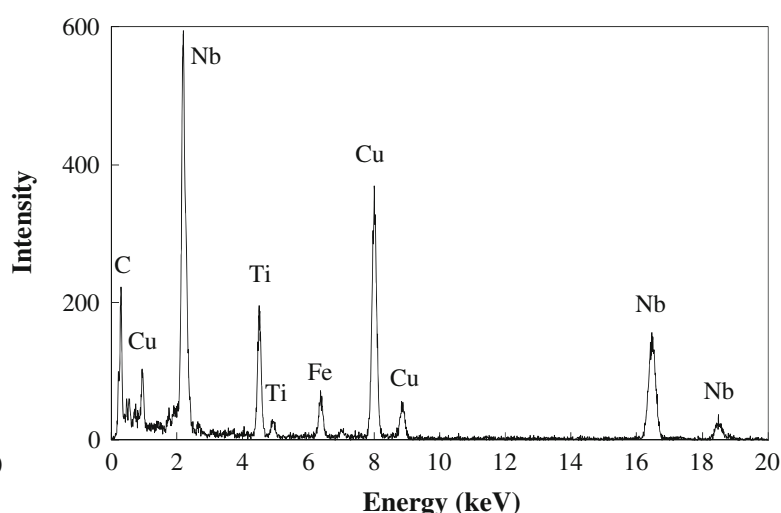

(c)

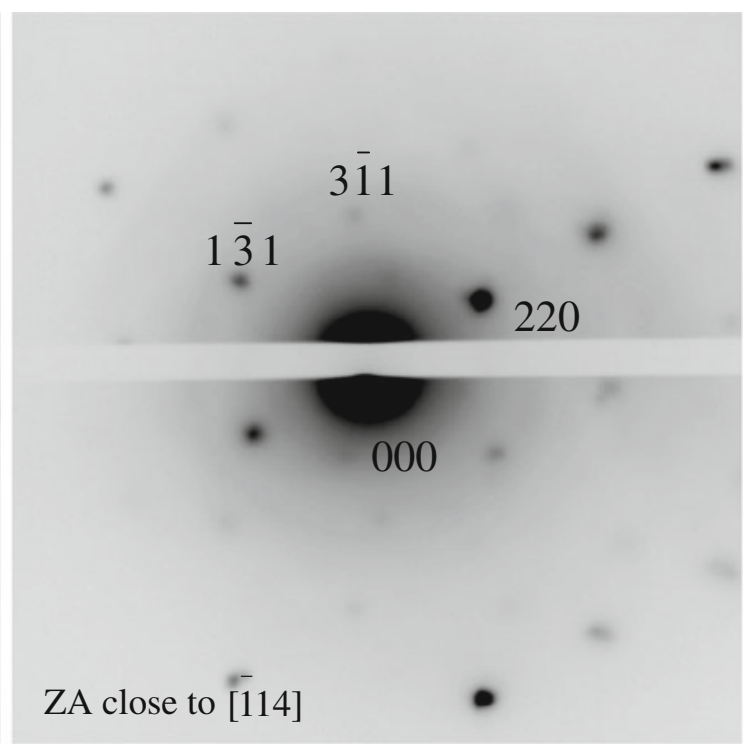

(e)

Fig. 6-(a) TEM BF image of Nb-rich precipitates attached to a Ti-rich precipitate, extracted by electrolytic dissolution using 10 pct AA. (b) EDX spectrum from Ti-rich precipitate in $(a)$. $(c)$ EDX spectrum from one of the Nb-rich precipitates in $(a)$. (d) SAD pattern from overlapping Ti-rich and Nb-rich precipitates (interface 1/2) in (a). (e) SAD pattern from Ti-rich precipitate in $(a)$. 


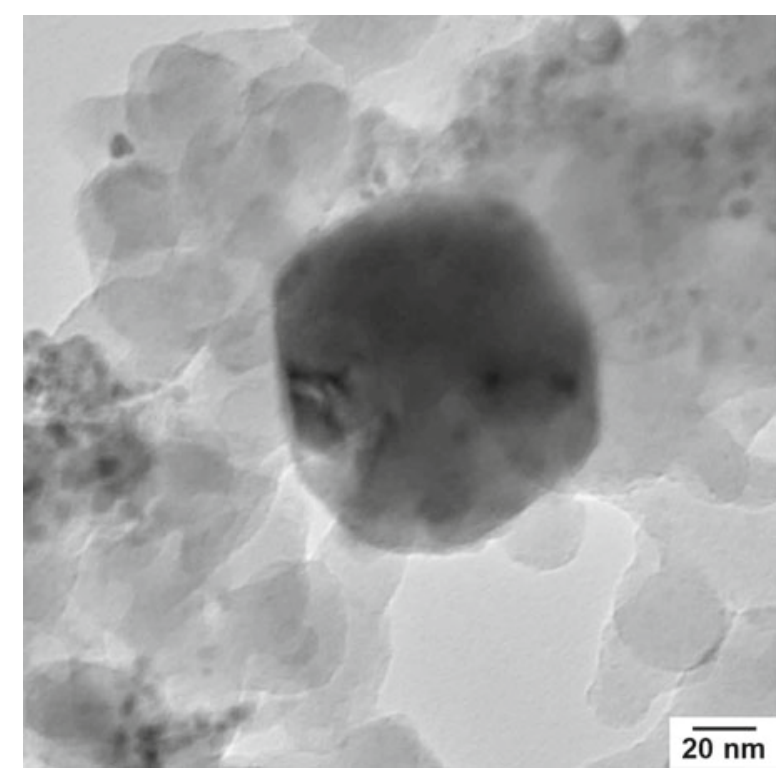

(a)

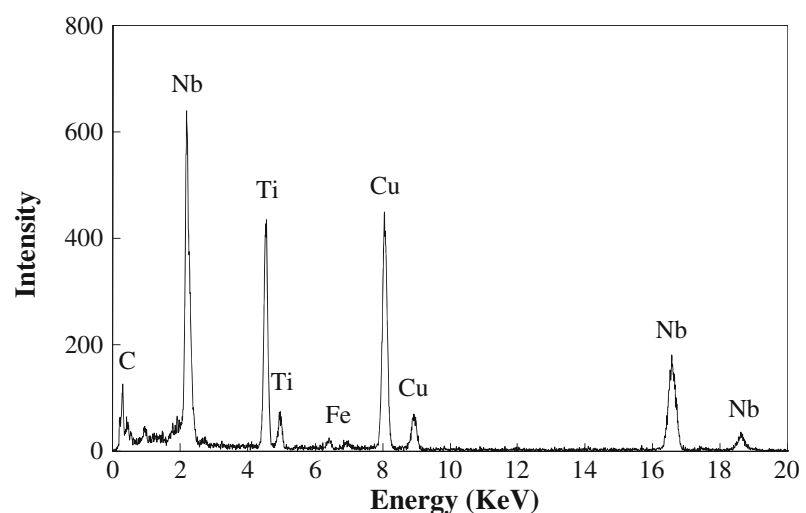

(b)

Fig. 7-(a) TEM BF image of an intermediate-sized Ti/Nb-rich precipitate extracted by chemical dissolution using HCl. (b) EDX spectrum from the precipitate shown in $(a)$.

precipitates (300 to $3000 \mathrm{~nm}$ ) are formed at higher temperatures (during or soon after casting) and are expected to contain little or no $\mathrm{C}$, so the composition is listed as $\operatorname{Ti}(\mathrm{Nb}) \mathrm{N}$. The intermediate-size Ti-rich (100 to $300 \mathrm{~nm})$, Nb-rich and Ti/Nb-rich (100 to $200 \mathrm{~nm})$ precipitates are formed during the rolling process. These contain both $\mathrm{C}$ and $\mathrm{N}$. To simplify the calculations (at least initially), the $\mathrm{C}$ and $\mathrm{N}$ amounts are assumed to be similar. (The actual composition could vary somewhat from this simplifying assumption.) Nanoprecipitates $(\leq 10 \mathrm{~nm}, \mathrm{Nb} /$ Mo-rich) are formed at much lower temperatures (during or after coiling). It is expected that they are primarily carbides. The expectation and assumptions are based on precipitate solubilities. ${ }^{[3]}$ Matrix dissolution and carbon replicas yield consistent results for precipitate size and chemistry; in addition carbon replicas help to validate the matrix dissolution technique.

\section{Rietveld refinement of the XRD data}

A detailed analysis of the XRD patterns was obtained via Rietveld refinement. Figure 10 shows the profile fitting of the XRD pattern for residues obtained from the Grade100 steel by electrolytic dissolution. Five phases are superimposed on the observed diffraction pattern. Figure 10(a) shows the overall profile fitting and the difference between the calculated and observed spectrum. Figures 10(b) through (f) show the calculated diffraction patterns for $\mathrm{Ti}_{0.9} \mathrm{Nb}_{0.1} \mathrm{~N}, \mathrm{Ti}_{0.77^{-}}$ $\mathrm{Nb}_{0.23} \mathrm{C}_{0.5} \mathrm{~N}_{0.5}, \quad \mathrm{Ti}_{0.5} \mathrm{Nb}_{0.5} \mathrm{C}_{0.5} \mathrm{~N}_{0.5}, \quad \mathrm{Nb}_{0.7} \mathrm{Ti}_{0.3} \mathrm{C}_{0.5} \mathrm{~N}_{0.5}$, and $\mathrm{Nb}_{0.48} \mathrm{Mo}_{0.28} \mathrm{Ti}_{0.21} \mathrm{~V}_{0.03} \mathrm{C}$, respectively, as indicated by arrows. These precipitate phases were determined through TEM analysis in Table IV. The tick marks at the bottom of the figures indicate the peak positions for the previously mentioned phases. The lattice parameters for the five types of precipitates are similar and are listed in Table V. The smallest precipitates (3 to $5 \mathrm{~nm}$ in size) are attributed to $\mathrm{Nb}_{0.48} \mathrm{Mo}_{0.28} \mathrm{Ti}_{0.21} \mathrm{~V}_{0.03} \mathrm{C}$.

Rietveld refinement was also carried out on XRD patterns from residues produced by chemical dissolution. The profile fitting of the XRD pattern for the residues from chemical dissolution, as shown in Figure 11, is slightly different from that by electrolytic dissolution. Because nanoprecipitates (mostly $\leq 10 \mathrm{~nm}$ ) with chemistry $\mathrm{Nb}_{0.48} \mathrm{Mo}_{0.28} \mathrm{Ti}_{0.21} \mathrm{~V}_{0.03} \mathrm{C}$ have broad peaks, there is a strong correlation (peak overlap) with amorphous $\mathrm{SiO}_{2}$, i.e., the nanoprecipitate information is contained within the amorphous $\mathrm{SiO}_{2}$ information. Therefore, the nanoprecipitate phase and amorphous $\mathrm{SiO}_{2}$ are considered together as one phase in the Rietveld refinement. As such, the amount of nanoprecipitates is not determined directly from the Rietveld refinement. $\mathrm{SiO}_{2}$ was used as an internal standard, and the resulting residual amorphous content is ascribed to the nanoprecipitates. The amount of $\mathrm{SiO}_{2}$ is determined from the $\mathrm{Si}$ content in the residue, which was obtained indirectly from the total amount of $\mathrm{Si}$ in the steel minus the amount in the supernatant (from ICP analysis; Table III). To apply Rietveld refinement to the amorphous $\mathrm{SiO}_{2}$ structure, a crystalline form of silica, cristobalite, is used to approximate the amorphous phase. Cristobalite has a tetragonal structure $(a=0.49732 \mathrm{~nm}, c=0.69236 \mathrm{~nm}),{ }^{[26]}$ with the same composition and similar $d$ spacings to the major broad diffraction rings for amorphous $\mathrm{SiO}_{2}$. Figure 11(a) shows the overall profile fitting and the difference between the calculated and observed spectrum. Figures 11(b) through (f) show the calculated diffraction patterns (indicated by arrows) for $\mathrm{Ti}_{0.9} \mathrm{Nb}_{0.1} \mathrm{~N}, \mathrm{Ti}_{0.77^{-}}$ $\mathrm{Nb}_{0.23} \mathrm{C}_{0.5} \mathrm{~N}_{0.5}, \quad \mathrm{Ti}_{0.5} \mathrm{Nb}_{0.5} \mathrm{C}_{0.5} \mathrm{~N}_{0.5}, \quad \mathrm{Nb}_{0.7} \mathrm{Ti}_{0.3} \mathrm{C}_{0.5} \mathrm{~N}_{0.5}$, and the nanoprecipitates + amorphous $\mathrm{SiO}_{2}$. The tick marks in the bottom of the figures indicate the $d$-spacing positions for the previously mentioned phases. 


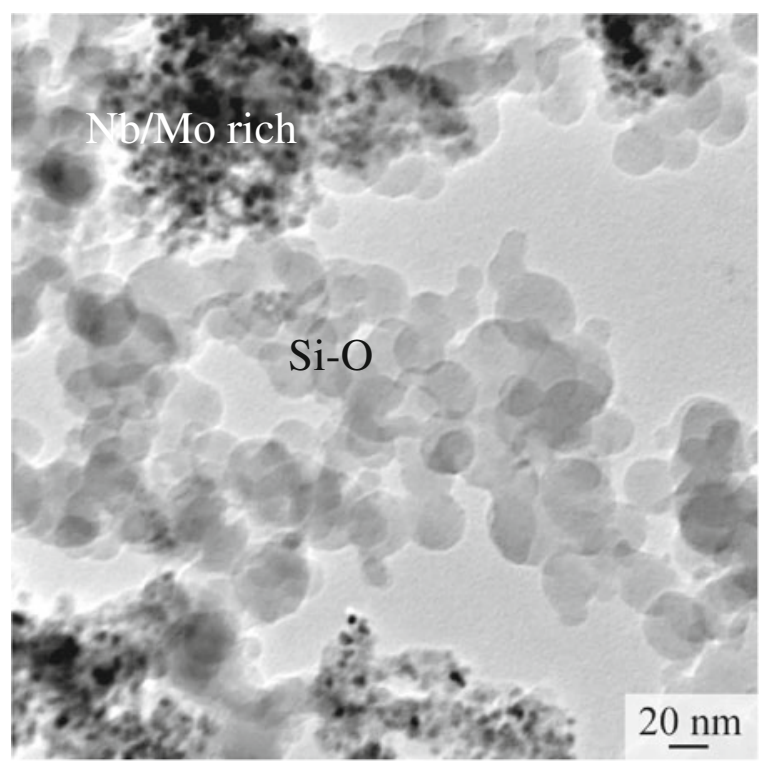

(a)

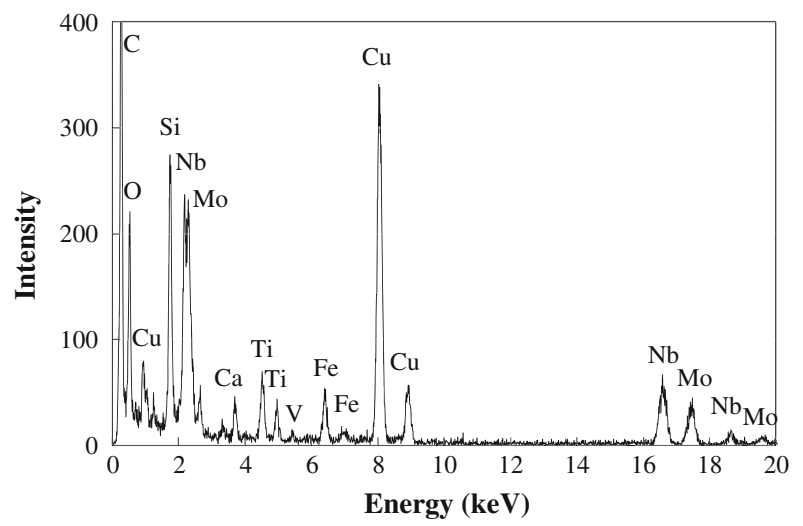

(c)

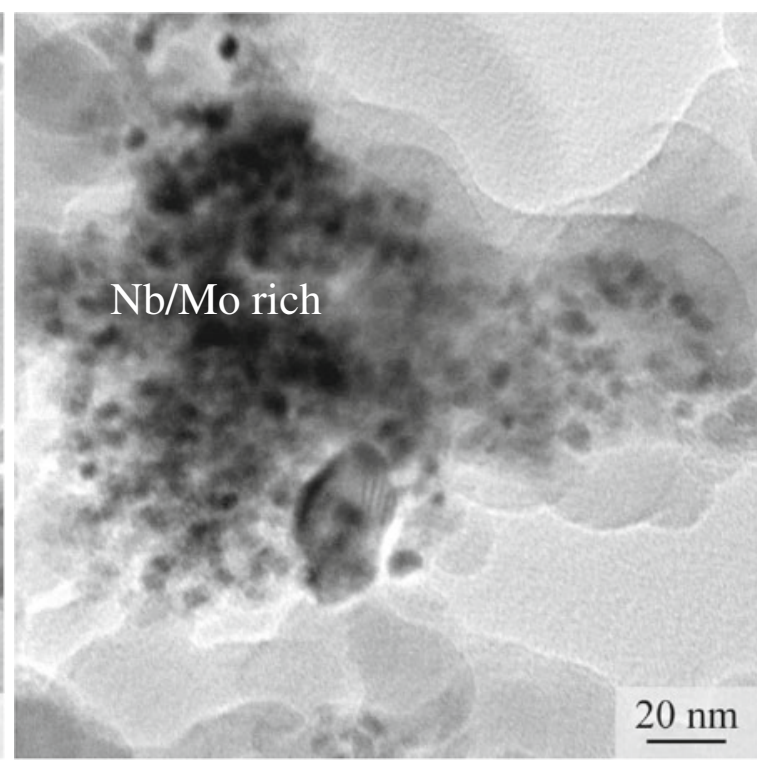

(b)

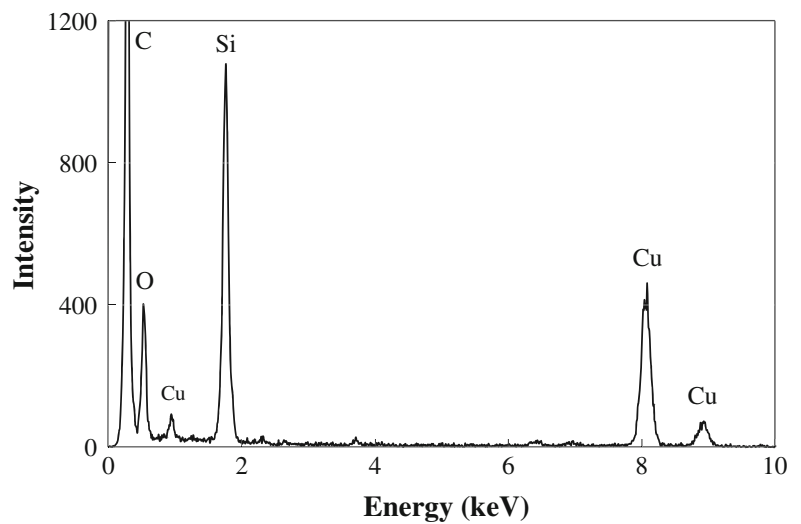

(d)

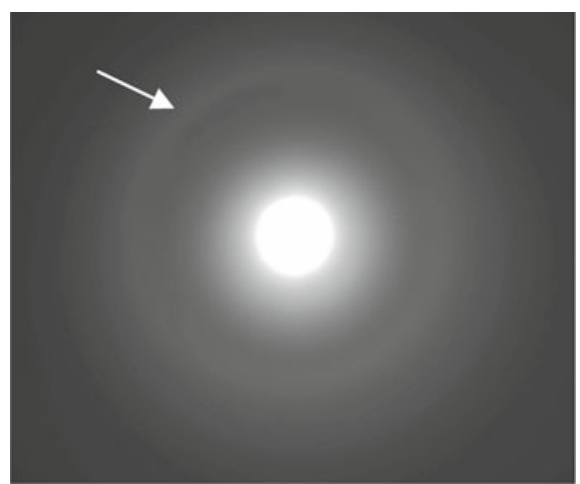

(e)

Fig. 8- $(a$ and $b)$ TEM BF image of fine Nb/Mo-rich precipitates extracted by chemical dissolution using HCl. (c) EDX spectrum from $\mathrm{Nb} /$ Mo-rich precipitates shown in $(b)$. (d) EDX spectrum from Si-O phase shown in $(a)$. (e) SAD of Si-O phase shown in $(a)$, indicating amorphous structure.

The goodness of fit can be evaluated from the difference plot between the observed and calculated data or by the Bragg $R$-index $\left(R_{\mathrm{Bragg}}\right)$. The difference plot, $y_{i}(\mathrm{obs})-y_{i}(\mathrm{calc})$, is the gray line at the bottom of the fitted profiles (Figures 10 and 11). $R_{\text {Bragg }}$ implies a comparison of integrated intensities similar to single crystal refinement. $R_{\text {Bragg }}$ and the lattice parameters for the different phases in the residues from electrolytic and chemical dissolution are shown in Table $\mathrm{V}$. The lattice parameters were calculated from the $d$ spacings determined from the 


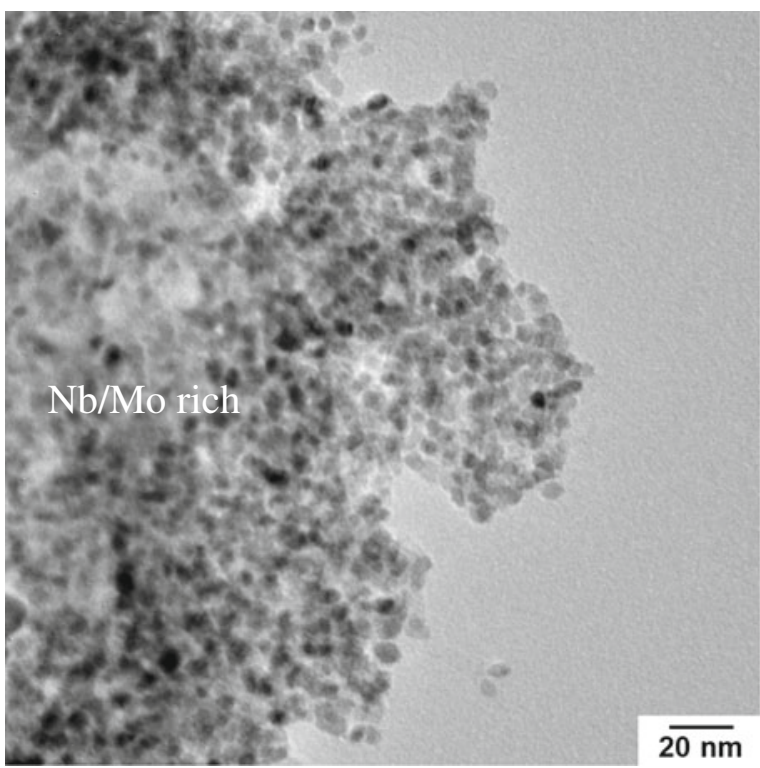

(a)

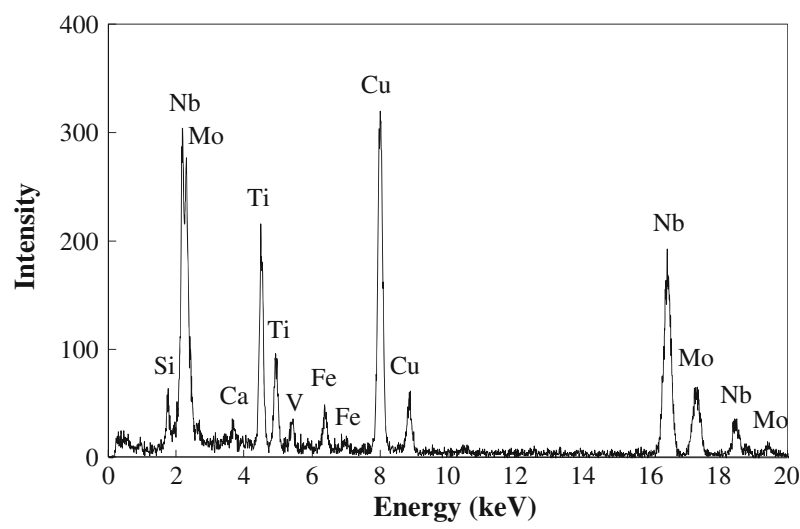

(b)

Fig. 9-(a) TEM BF image of fine Nb/Mo-rich precipitates extracted by electrolytic dissolution using 10 pct AA. (b) EDX spectrum from precipitates shown in $(a)$.

Table IV. Classification of Precipitates According to Composition and Size Range Determined from TEM Analysis

\begin{tabular}{llrc}
\hline $\begin{array}{l}\text { Precipitate } \\
\text { Chemistry }\end{array}$ & $\begin{array}{l}\text { Standard Deviation } \\
\text { for Composition }\end{array}$ & $\begin{array}{c}\text { Size } \\
\text { in Atomic Fraction }\end{array}$ & $\begin{array}{c}\text { Range } \\
\text { (nm) }\end{array}$ \\
\hline $\mathrm{Ti}_{0.9} \mathrm{Nb}_{0.1} \mathrm{~N}$ & $\mathrm{Ti}$ & 0.05 & 300 to 3000 \\
& $\mathrm{Nb}$ & 0.05 & \\
$\mathrm{Ti}_{0.77} \mathrm{Nb}_{0.23} \mathrm{C}_{0.5} \mathrm{~N}_{0.5}$ & $\mathrm{Ti}$ & 0.05 & 100 to 3000 \\
$\mathrm{Ti}_{0.5} \mathrm{Nb}_{0.5} \mathrm{C}_{0.5} \mathrm{~N}_{0.5}$ & $\mathrm{Nb}$ & 0.05 & \\
& $\mathrm{Ti}$ & 0.07 & 100 to 200 \\
$\mathrm{Nb}_{0.7} \mathrm{Ti}_{0.3} \mathrm{C}_{0.5} \mathrm{~N}_{0.5}$ & $\mathrm{Nb}$ & 0.07 & \\
& $\mathrm{Ti}$ & 0.05 & 100 to 200 \\
$\mathrm{Nb}_{0.48} \mathrm{Mo}_{0.28} \mathrm{Ti}_{0.21} \mathrm{~V}_{0.03} \mathrm{C}$ & $\mathrm{Nb}$ & 0.05 & \\
& $\mathrm{Ti}$ & 0.05 & $<10$ \\
& $\mathrm{Nb}$ & 0.05 & \\
\hline
\end{tabular}

XRD patterns. A comparison of the lattice parameters for the precipitates extracted by the two different dissolution methods shows good agreement, which is expected as the precipitates are from the same Grade 100 steel; only the extraction methods are different. $\mathrm{Ti}_{0.9} \mathrm{Nb}_{0.1} \mathrm{~N}$ has the smallest lattice parameter. The lattice parameter increases with increasing $\mathrm{Nb}$ content and decreases with increasing Mo and V content.

Calculations were done to determine whether the lattice parameters for the $\mathrm{Ti} / \mathrm{Nb}$ carbonitrides in Table V correlated with the compositions obtained from TEM analysis (Table IV). Lattice parameters for binary $\mathrm{Ti}$ and $\mathrm{Nb}$ carbides and nitrides are shown in Table VI; these were obtained from the International Center for Diffraction Data database. ${ }^{[26]}$

Because these binary phases all have the same crystal structure with similar lattice parameters, it is reasonable to assume that the lattice parameters for the ternary phases $(\mathrm{Ti} / \mathrm{Nb}$ carbides, $\mathrm{Ti} / \mathrm{Nb}$ nitrides, or $\mathrm{Ti} / \mathrm{Nb}$ carbonitrides) can be estimated by linear interpolation between the appropriate binary phases. For example, the lattice parameter for $\mathrm{Ti}_{x} \mathrm{Nb}_{1-x} \mathrm{~N}$ can be calculated by linearly interpolating between the lattice parameters for TiN and $\mathrm{NbN}$ for the desired value of $x$. This process can be used in reverse, i.e., the composition of a particular precipitate can be determined if its lattice parameter is known. The calculations were done using the lattice parameters for the first four precipitates in Table V; the fifth precipitate was excluded because of the compositional complexity (four transition metal components). Two assumptions were made. The first precipitate in Table IV was assumed to be a nitride (no carbon) to determine the $\mathrm{Ti}$ and $\mathrm{Nb}$ compositions. This assumption is reasonable as it is the largest precipitate, forms at the highest temperature, and, as such, is expected to contain little or no C. The other three precipitates were assumed to be carbonitrides. The Ti and $\mathrm{Nb}$ compositions, which were obtained from a TEM analysis, were taken as correct, so that the $\mathrm{C}$ and $\mathrm{N}$ compositions could be determined. Note that in Table IV, the $\mathrm{C}$ and $\mathrm{N}$ amounts were assumed to be 0.5 in the precipitate formulae because the $\mathrm{C}$ and $\mathrm{N}$ compositions could not be determined from EDX analysis. The resultant precipitate compositions are shown in Table VII. The first precipitate ( $\mathrm{Ti} / \mathrm{Nb}$ nitride) in the table shows good agreement with the composition obtained from TEM EDX analysis (Table IV), i.e., the difference is within one standard deviation. For the other three precipitates, the relative $\mathrm{N}$ and $\mathrm{C}$ compositions show the correct trend, i.e., the $\mathrm{C}$ amount increases as the precipitates become more $\mathrm{Nb}$ rich (Ti deficient).

As mentioned previously, $\mathrm{Al}$ is added primarily as a deoxidizer in steel and works in conjunction with silicon. Aluminum is normally dissolved in austenite at high 


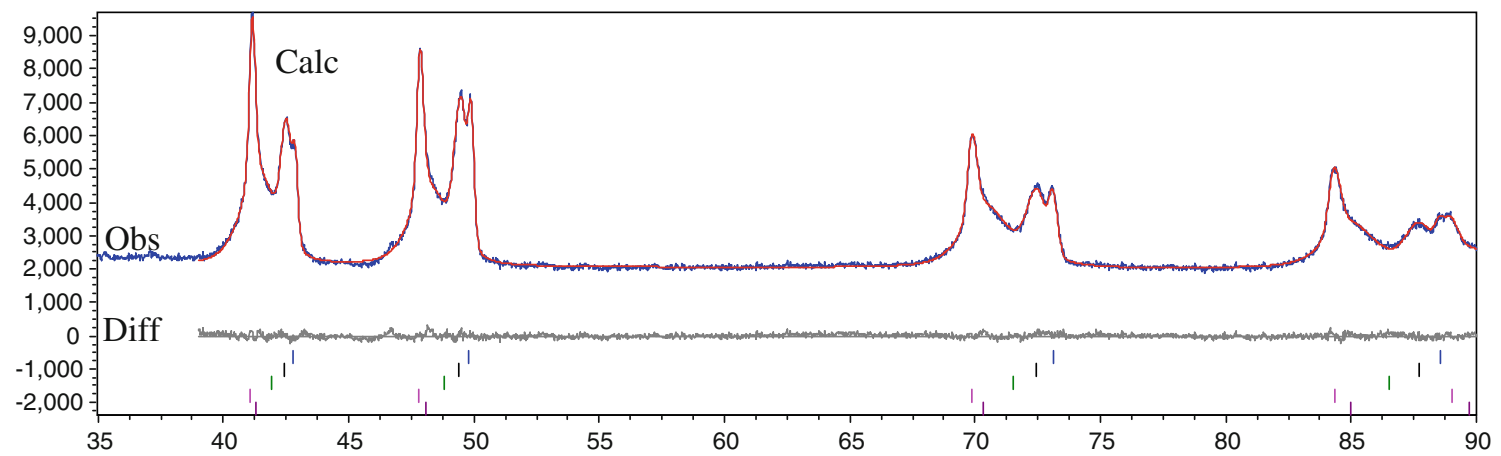

(a)

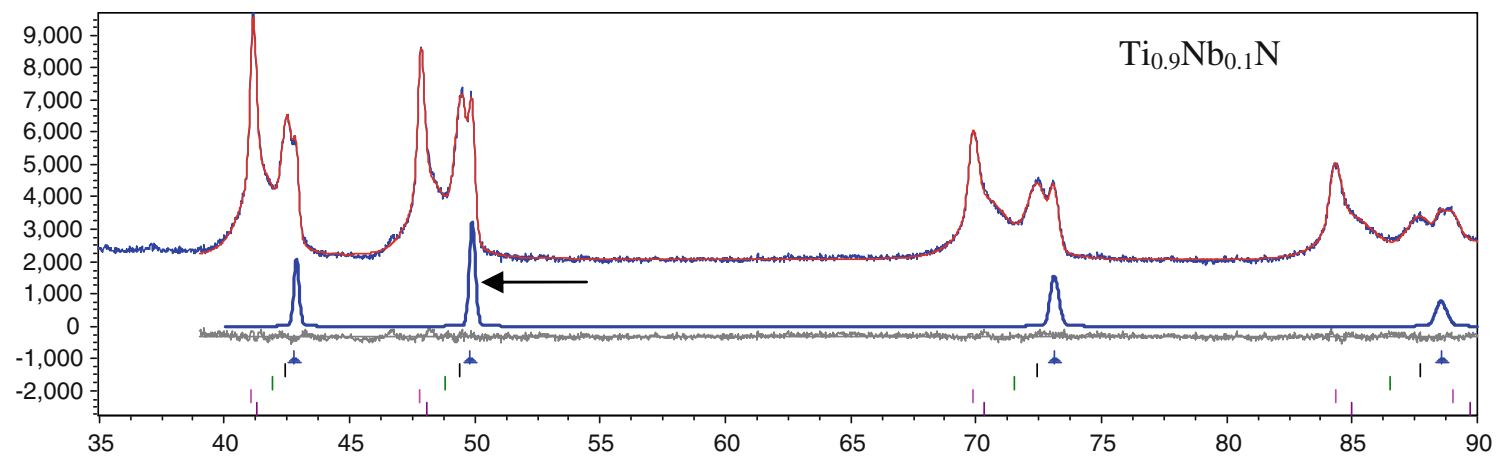

(b)

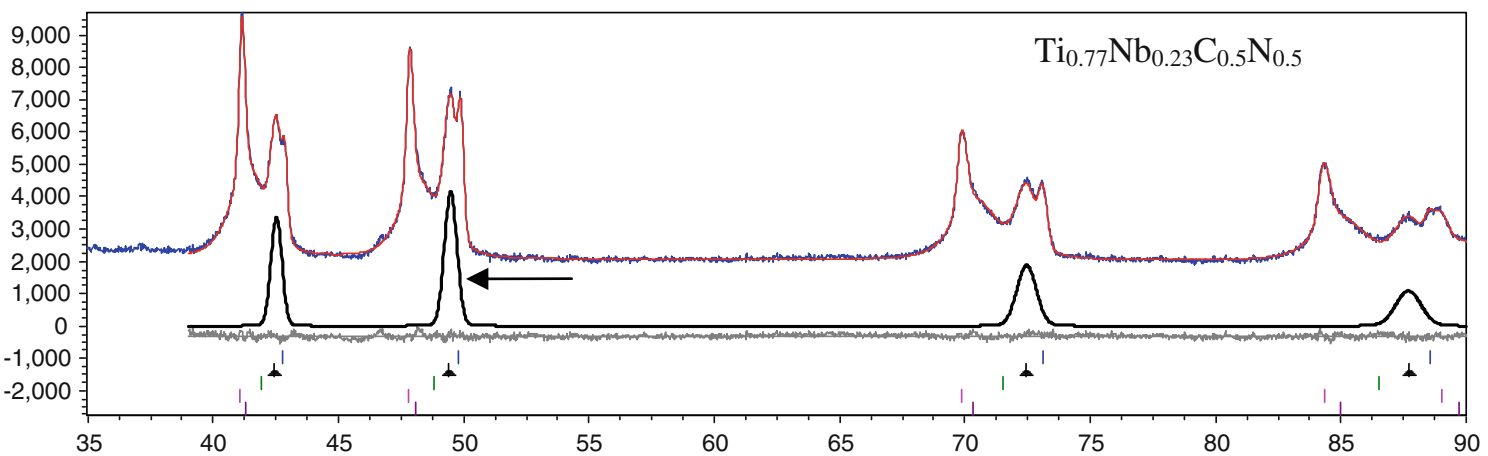

(c)

Fig. 10-Profile fitting of XRD pattern by Rietveld refinement for precipitates from Grade100 steel, electrolytically dissolved using 10 pct AA dissolution. (a) Overall XRD pattern profile fitting, (b) calculated diffraction pattern for $\mathrm{Ti}_{0.9} \mathrm{Nb}_{0.1} \mathrm{~N}$, (c) calculated diffraction pattern for $\mathrm{Ti}_{0.77} \mathrm{Nb}_{0.23} \mathrm{C}_{0.5} \mathrm{~N}_{0.5},(d)$ calculated diffraction pattern for $\mathrm{Ti}_{0.5} \mathrm{Nb}_{0.5} \mathrm{C}_{0.5} \mathrm{~N}_{0.5}$, (e) calculated diffraction pattern for $\mathrm{Nb}_{0.7} \mathrm{Ti}_{0.3} \mathrm{C}_{0.5} \mathrm{~N}_{0.5}$, and $(f)$ calculated diffraction pattern for $\mathrm{Nb}_{0.48} \mathrm{Mo}_{0.28} \mathrm{Ti}_{0.21} \mathrm{~V}_{0.03} \mathrm{C}$. Obs: observed diffraction pattern; Calc: calculated diffraction pattern; Diff: difference between the calculated and observed pattern.

temperatures prior to rolling. The nitride phase (AIN) has a low solubility product in steel, and it is thermodynamically stable at lower temperatures. ${ }^{[7,16]}$ However, AlN has a high nucleation barrier because of its hexagonal crystal structure, i.e., a different morphology from the other FCC nitrides. ${ }^{[16,27]}$ AlN nucleates with some difficulty in steel unless precipitation is enhanced by thermal or mechanical treatments. ${ }^{[17]}$ In addition, TiN has an even lower solubility product than AlN. Thermodynamic calculations and experimental work have shown that AlN is not present in this Grade100 steel. ${ }^{[4,11]}$

In addition to precipitates, some Al- and Ca-containing inclusions were observed by optical microscopy or
SEM. They were not studied in detail in this article, as they do not contribute to the strength.

Manganese was not detected in the precipitates. This is consistent with the previous statement that Mn primarily provides solid solution strengthening. ${ }^{[15]}$ It should be noted that some $\mathrm{Mn}$ combines with sulfur to form $\mathrm{MnS}$. However, as with $\mathrm{Fe}_{3} \mathrm{C}, \mathrm{MnS}$ is unstable in acid. Both $\mathrm{Fe}_{3} \mathrm{C}$ and $\mathrm{MnS}$ cannot be extracted by acid solutions, as reported by Kanazawa et al. ${ }^{[28]}$ and Bandi. ${ }^{[29]}$

Iron has been found in small $\mathrm{Nb} / \mathrm{Mo} / \mathrm{V} / \mathrm{Ti}$ carbides, which indicates that the precipitates may have nonequilibrium compositions. ${ }^{[4]}$ The addition of iron to the NaCl-type lattice of transition metal carbonitrides 


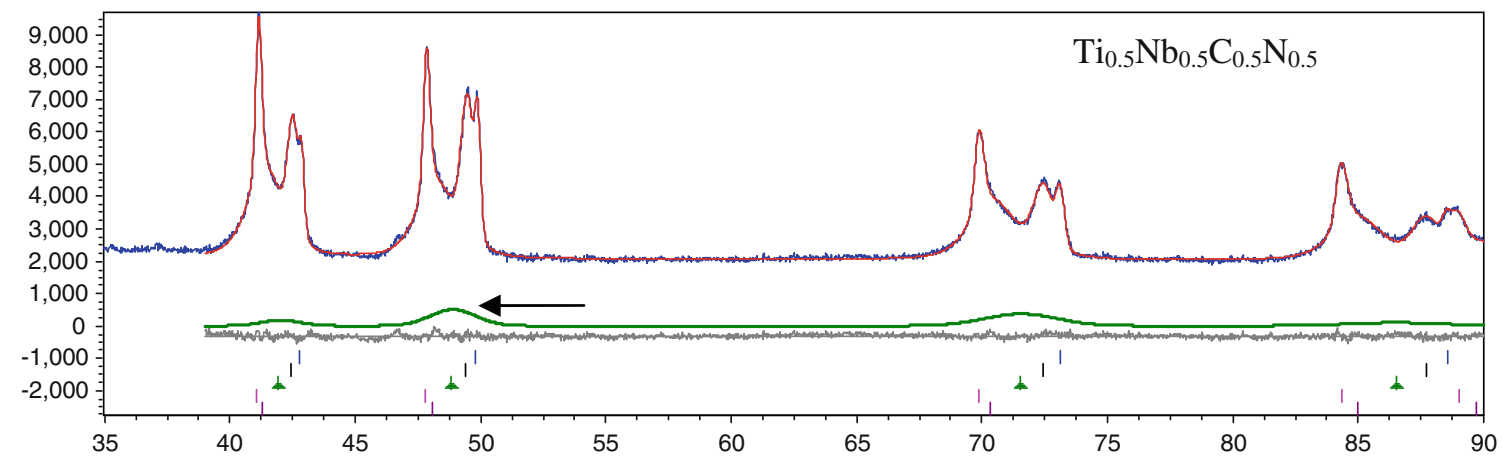

(d)

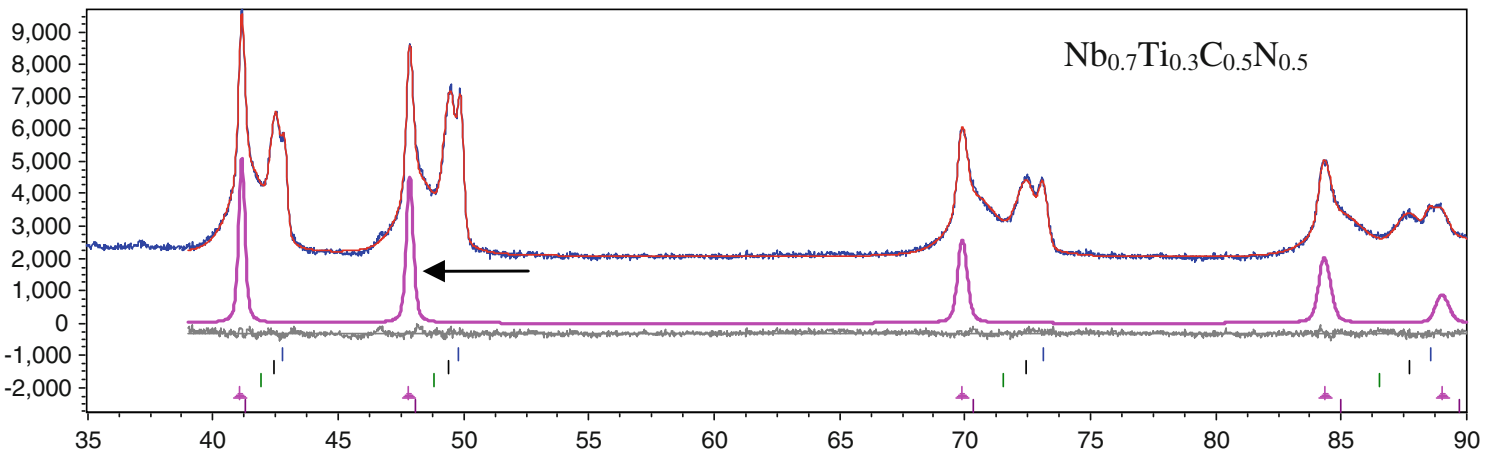

(e)

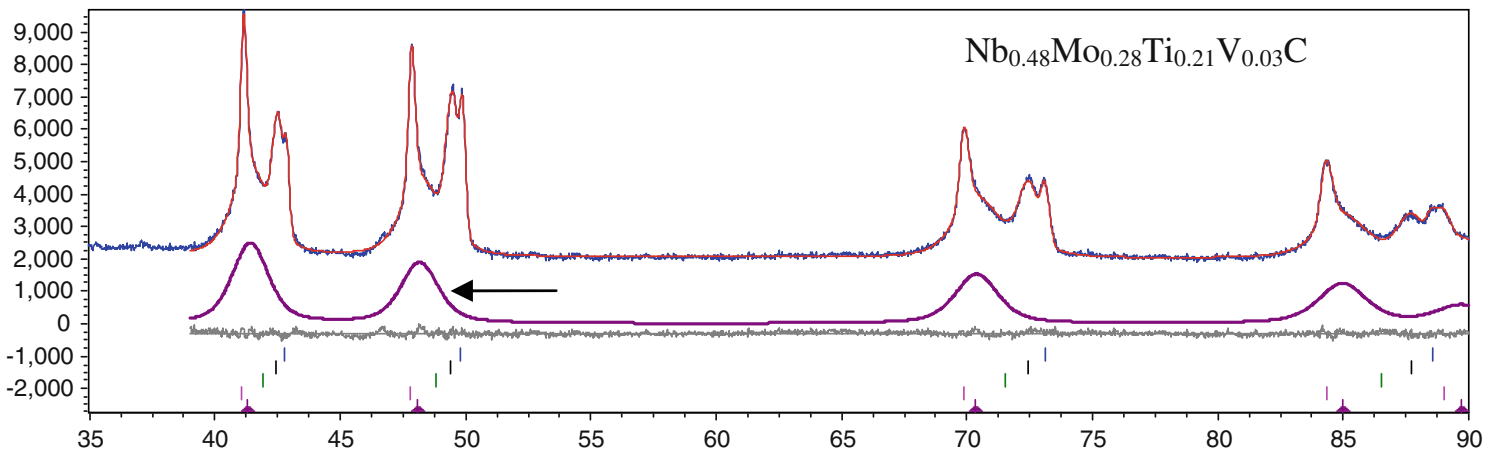

(f)

Fig. $10-$ Continued.

Table V. Bragg $R$-Index $\left(R_{\text {Bragg }}\right)$ and Lattice Parameters for Different Phases in Grade100 Steel by Two Dissolution Methods

\begin{tabular}{lcccc}
\hline & \multicolumn{2}{c}{ Electrolytic $(10$ pct AA) } & \multicolumn{2}{c}{ Chemical $(\mathrm{HCl})$} \\
\cline { 2 - 4 } Phases & $R_{\text {Bragg }}$ & Lattice Parameters (nm) & $R_{\text {Bragg }}$ & Lattice Parameters (nm) \\
\hline $\mathrm{Ti}_{0.9} \mathrm{Nb}_{0.1} \mathrm{~N}$ & 0.568 & 0.4248 & 2.145 & 0.4250 \\
$\mathrm{Ti}_{0.77} \mathrm{Nb}_{0.23} \mathrm{C}_{0.5} \mathrm{~N}_{0.5}$ & 0.426 & 0.4282 & 1.062 & 0.4282 \\
$\mathrm{Ti}_{0.5} \mathrm{Nb}_{0.5} \mathrm{C}_{0.5} \mathrm{~N}_{0.5}$ & 0.085 & 0.4329 & 0.173 & 0.4329 \\
$\mathrm{Nb}_{0.7} \mathrm{Ti}_{0.3} \mathrm{C}_{0.5} \mathrm{~N}_{0.5}$ & 0.107 & 0.4418 & 0.580 & 0.4419 \\
$\mathrm{Nb}_{0.48} \mathrm{Mo}_{0.28} \mathrm{Ti}_{0.21} \mathrm{~V}_{0.03} \mathrm{C}$ & 0.078 & 0.4392 & 0.108 & 0.4622 \\
$\mathrm{SiO}_{2}$ & N/A & N/A & \\
\hline
\end{tabular}




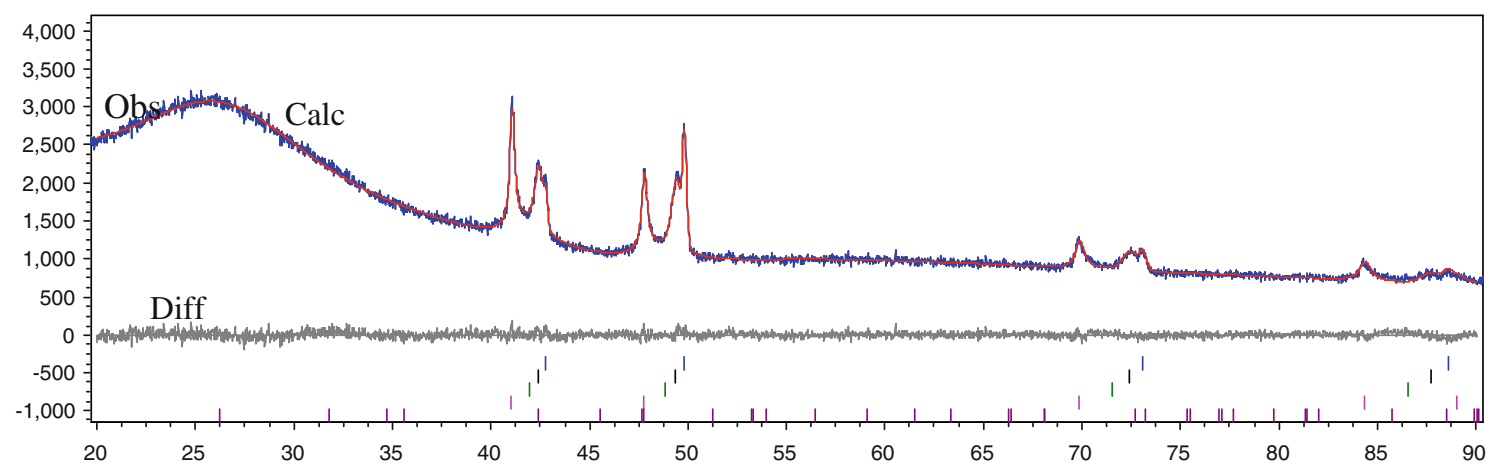

(a)

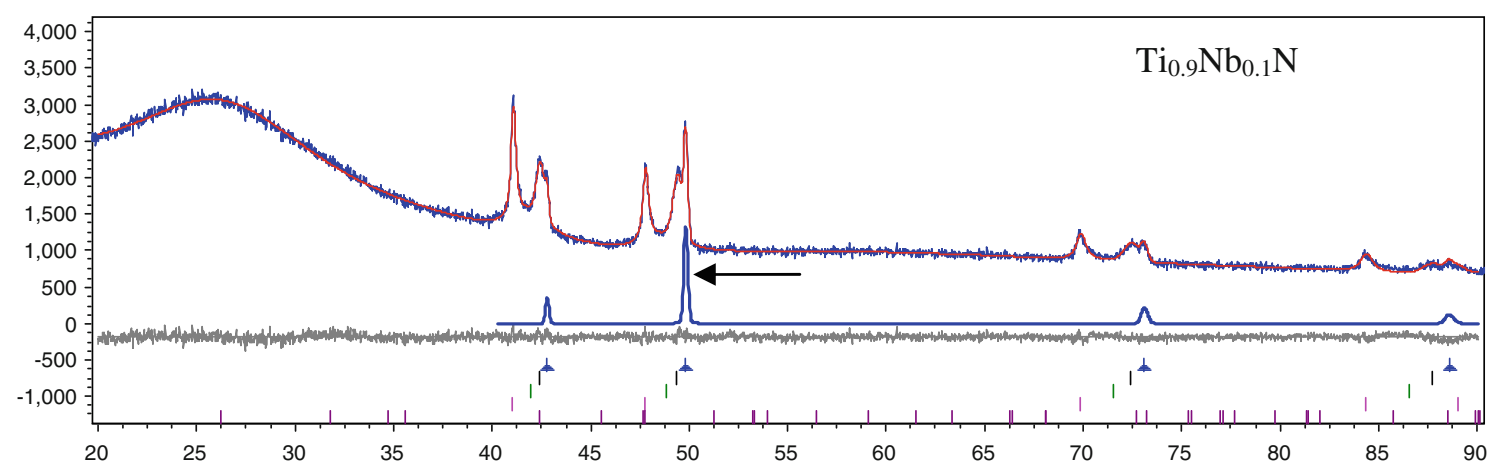

(b)

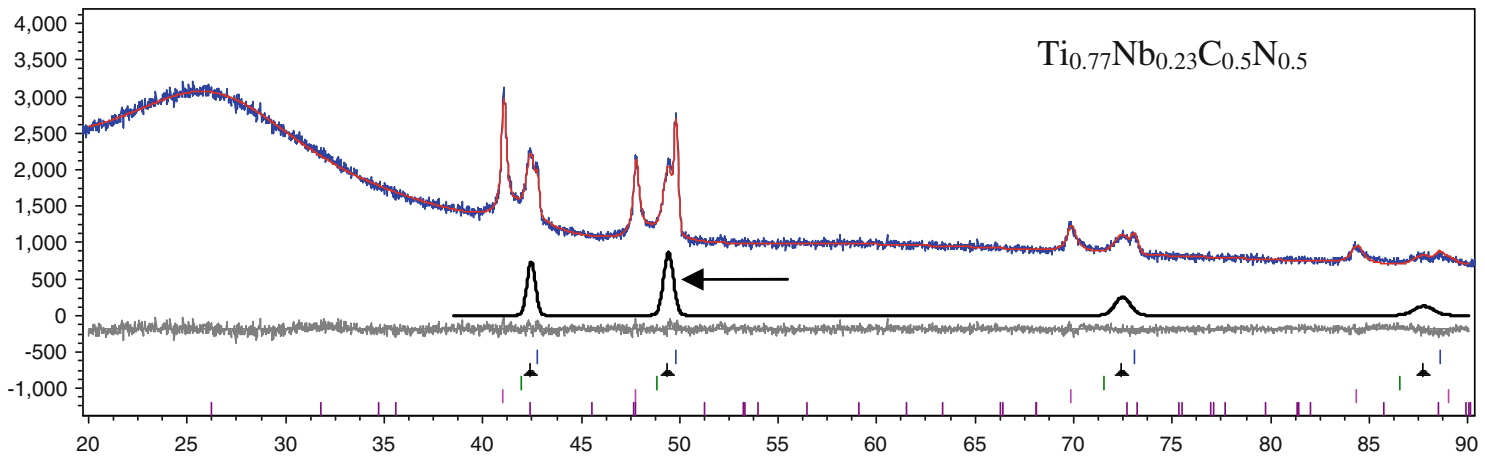

(c)

Fig. 11-Profile fitting of XRD pattern by Rietveld refinement for residue from Grade100 steel, chemically dissolved using HCl dissolution. (a) Overall XRD pattern profile fitting, (b) calculated diffraction pattern for $\mathrm{Ti}_{0.9} \mathrm{Nb}_{0.1} \mathrm{~N}, \quad(c)$ calculated diffraction pattern for $\mathrm{Ti}_{0.77} \mathrm{Nb}_{0.23} \mathrm{C}_{0.5} \mathrm{~N}_{0.5}$, (d) calculated diffraction pattern for $\mathrm{Ti}_{0.5} \mathrm{Nb}_{0.5} \mathrm{C}_{0.5} \mathrm{~N}_{0.5}$, (e) calculated diffraction pattern for $\mathrm{Nb}_{0.7} \mathrm{Ti}_{0.3} \mathrm{C}_{0.5} \mathrm{~N}_{0.5}$, and $(f)$ calculated diffraction pattern for amorphous $\mathrm{SiO}_{2}$ and nanoprecipitates. Obs: observed diffraction pattern; Calc: calculated diffraction pattern; Diff: difference between the calculated and observed pattern.

results in formation of an $(\mathrm{Fe}, \mathrm{M})_{x} \mathrm{C}_{y} \mathrm{~N}_{z}$ compound. ${ }^{[4]}$ Additional study is needed to understand whether the presence of $\mathrm{Fe}$ in the EDX spectra in this work (e.g., Figure 4) is from the steel matrix or from an $(\mathrm{Fe}, \mathrm{M})_{x} \mathrm{C}_{y} \mathrm{~N}_{z}$ compound.

\section{DISCUSSION}

\section{A. Determination of the Relative Abundance of Different Phases via Rietveld Refinement}

The relative abundance (expressed as wt pct) of the constituent crystalline phases in the extracted residue was determined from Eq. [2] by Rietveld refinement and is shown in Table VIII (electrolytic dissolution) and Table IX (chemical dissolution). The total wt pct of precipitates relative to the amount of steel is also shown in these tables, as is the amount of each precipitate relative to the steel.

It is clear that nanoprecipitates with an average composition of $\mathrm{Nb}_{0.48} \mathrm{Mo}_{0.28} \mathrm{Ti}_{0.21} \mathrm{~V}_{0.03} \mathrm{C}(\leq 10 \mathrm{~nm})$ are the majority crystalline phase in both chemically and electrolytically extracted residues. The relative amounts differed by approximately $10 \mathrm{pct}$, i.e., $0.140 \mathrm{wt}$ pct (electrolytic dissolution) and $0.157 \mathrm{wt}$ pct (chemical dissolution), respectively. However, there is relatively poor agreement for the other types of precipitates with 


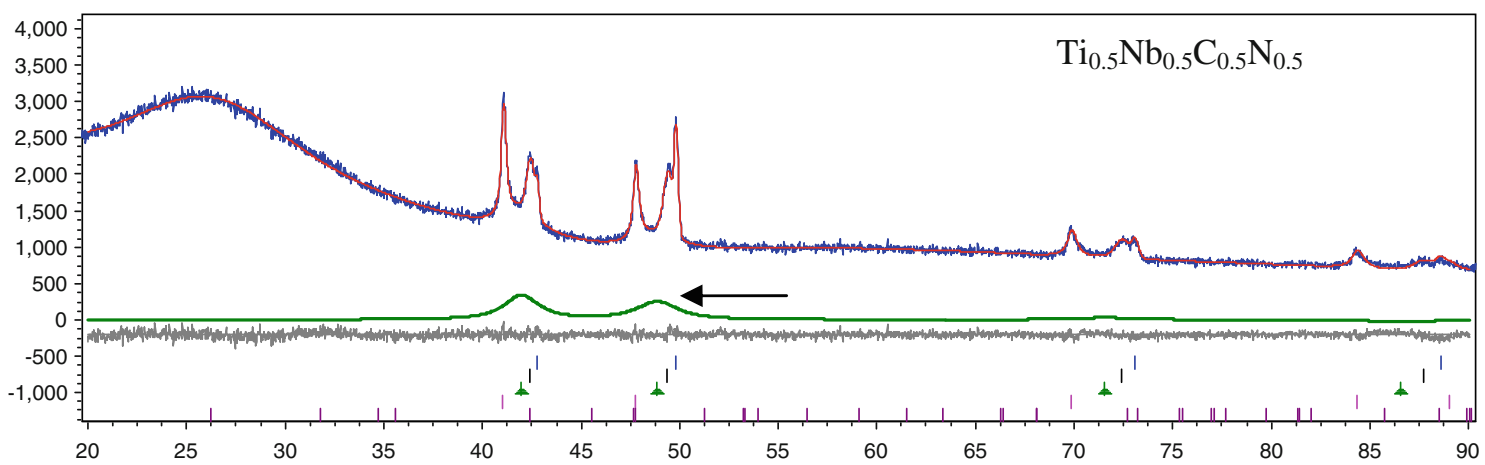

(d)

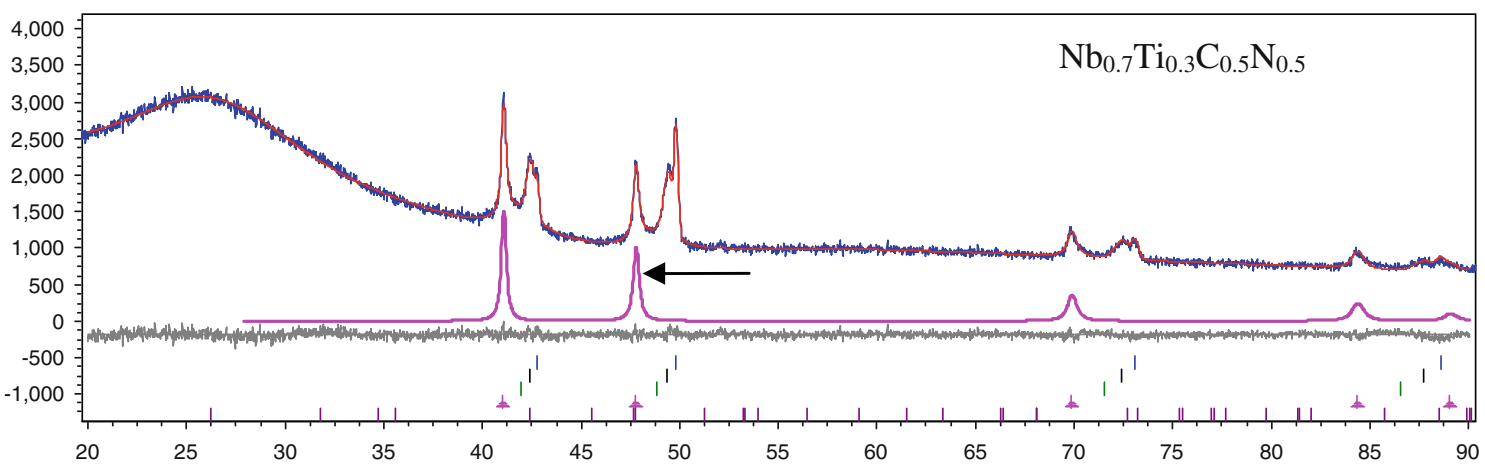

(e)

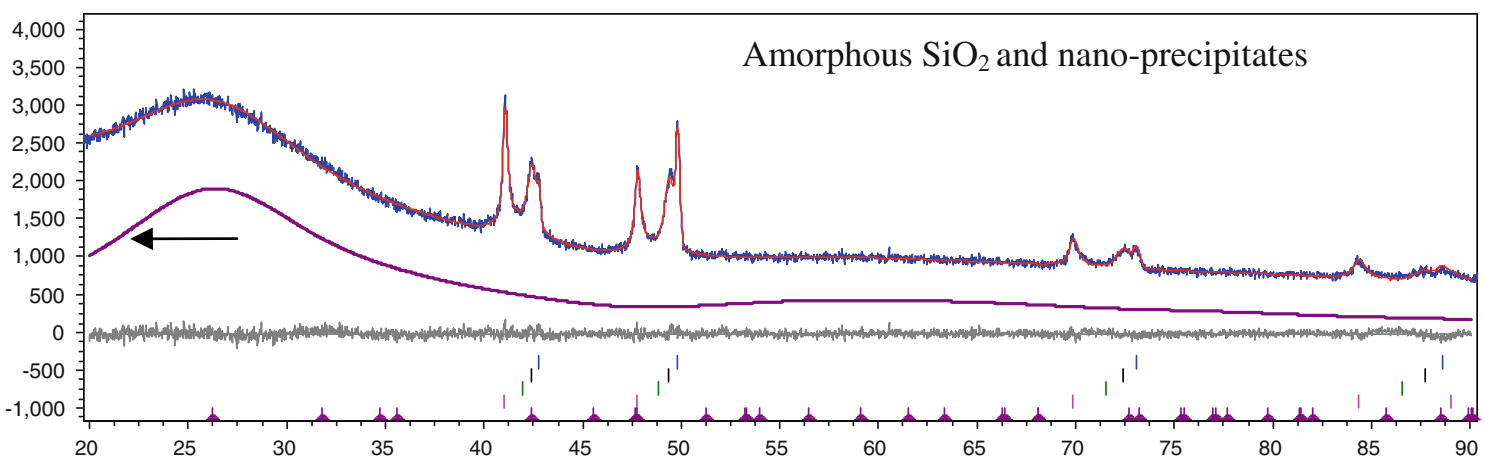

(f)

Fig. 11-Continued.

Table VI. Lattice Parameters for Binary Carbides and Nitrides

\begin{tabular}{lcccc}
\hline $\begin{array}{l}\text { Lattice } \\
\text { Parameter }(\mathrm{nm})\end{array}$ & $\mathrm{TiN}$ & $\mathrm{TiC}$ & $\mathrm{NbN}$ & $\mathrm{NbC}$ \\
\hline$a$ & 0.42417 & 0.43274 & 0.43927 & 0.44698 \\
\hline
\end{tabular}

the two extraction methods. There are two possible reasons for the discrepancy. First, there is a large amount of amorphous $\mathrm{SiO}_{2}$ in the chemically extracted residue, which could affect those results. Second, a smaller amount of precipitates produced by electrolytic dissolution was used for XRD analysis (approximately 10 pct of the mass used for chemical dissolution) because of the inefficiency in precipitate extraction. Therefore, errors could be amplified, especially for the
Table VII. C and N Content Calculations in Precipitates Using Two Dissolution Methods

\begin{tabular}{lll}
\hline $\begin{array}{l}\text { Dissolution } \\
\text { Method }\end{array}$ & Electrolytic (10 pct AA) & \multicolumn{1}{c}{ Chemical $(\mathrm{HCl})$} \\
\hline Precipitate & $\mathrm{Ti}_{0.96} \mathrm{Nb}_{0.04} \mathrm{~N}$ & $\mathrm{Ti}_{0.95} \mathrm{Nb}_{0.05} \mathrm{~N}$ \\
& $\mathrm{Ti}_{0.77} \mathrm{Nb}_{0.23} \mathrm{C}_{0.07} \mathrm{~N}_{0.93}$ & $\mathrm{Ti}_{0.77} \mathrm{Nb}_{0.23} \mathrm{C}_{0.07} \mathrm{~N}_{0.93}$ \\
& $\mathrm{Ti}_{0.5} \mathrm{Nb}_{0.5} \mathrm{C}_{0.14} \mathrm{~N}_{0.86}$ & $\mathrm{Ti}_{0.5} \mathrm{Nb}_{0.5} \mathrm{C}_{0.14} \mathrm{~N}_{0.86}$ \\
& $\mathrm{Nb}_{0.7} \mathrm{Ti}_{0.3} \mathrm{C}_{0.89} \mathrm{~N}_{0.11}$ & $\mathrm{Nb}_{0.7} \mathrm{Ti}_{0.3} \mathrm{C}_{0.90} \mathrm{~N}_{0.10}$ \\
\hline
\end{tabular}

minor precipitate phases. Overall, if the same amounts of residues are collected by both chemical and electrolytic dissolution methods, then the latter method should be more reliable because determination of the relative abundance of nanoprecipitates is not hindered by $\mathrm{SiO}_{2}$. However, electrolytic dissolution is much slower than 
Table VIII. Relative Abundance of Constituent Crystalline Phases Using Electrolytic Dissolution

\begin{tabular}{lccc}
\hline Phases & $\begin{array}{c}\text { Relative Abundance (wt pct) } \\
\text { of Precipitates in Residue }\end{array}$ & $\begin{array}{c}\text { Experimental Extraction } \\
\text { Yield (wt pct) }\end{array}$ & $\begin{array}{c}\text { Fraction of Precipitates Relative } \\
\text { to Mass of Steel Dissolved }\end{array}$ \\
\hline $\mathrm{Ti}_{0.96} \mathrm{Nb}_{0.04} \mathrm{~N}$ & $10.8 \mathrm{pct}$ & $0.361 \mathrm{pct}$ & $3.8 \times 10^{-4}$ \\
$\mathrm{Ti}_{0.77} \mathrm{Nb}_{0.23} \mathrm{C}_{0.07} \mathrm{~N}_{0.93}$ & $26.4 \mathrm{pct}$ & & $9.6 \times 10^{-4}$ \\
$\mathrm{Ti}_{0.5} \mathrm{Nb}_{0.5} \mathrm{C}_{0.14} \mathrm{~N}_{0.86}$ & $8.5 \mathrm{pct}$ & $3.1 \times 10^{-4}$ \\
$\mathrm{Nb}_{0.7} \mathrm{Ti}_{0.3} \mathrm{C}_{0.89} \mathrm{~N}_{0.11}$ & $15.5 \mathrm{pct}$ & $5.6 \times 10^{-4}$ \\
$\mathrm{Nb}_{0.48} \mathrm{Mo}_{0.28} \mathrm{Ti}_{0.21} \mathrm{~V}_{0.03} \mathrm{C}$ & $38.8 \mathrm{pct}$ & $1.4 \times 10^{-3}$ \\
\hline
\end{tabular}

Table IX. Relative Abundance of Constituent Crystalline Phases Using Chemical Dissolution

\begin{tabular}{lcrc}
\hline Phases & $\begin{array}{c}\text { Relative Abundance (wt pct) } \\
\text { of Precipitates in Residue }\end{array}$ & $\begin{array}{c}\text { Experimental Extraction } \\
\text { Yield (wt pct) }\end{array}$ & $\begin{array}{c}\text { Fraction of Precipitates Relative } \\
\text { to Mass of Steel Dissolved }\end{array}$ \\
\hline $\mathrm{Ti}_{0.96} \mathrm{Nb}_{0.05} \mathrm{~N}$ & $1.6 \mathrm{pct}$ & $0.792 \mathrm{pct}$ & $1.3 \times 10^{-4}$ \\
$\mathrm{Ti}_{0.77} \mathrm{Nb}_{0.23} \mathrm{C}_{0.07} \mathrm{~N}_{0.93}$ & $3.4 \mathrm{pct}$ & $2.7 \times 10^{-4}$ \\
$\mathrm{Ti}_{0.5} \mathrm{Nb}_{0.5} \mathrm{C}_{0.14} \mathrm{~N}_{0.86}$ & $0.8 \mathrm{pct}$ & $0.6 \times 10^{-4}$ \\
$\mathrm{Nb}_{0.7} \mathrm{Ti}_{0.3} \mathrm{C}_{0.90} \mathrm{~N}_{0.10}$ & $3.2 \mathrm{pct}$ & $2.5 \times 10^{-4}$ \\
$\mathrm{Nb}_{0.48} \mathrm{Mo}_{0.28} \mathrm{Ti}_{0.21} \mathrm{~V}_{0.03} \mathrm{C}$ & $19.8 \mathrm{pct}$ & $1.57 \times 10^{-4}$ \\
\hline
\end{tabular}

chemical dissolution. In any case, our main concern is the nanoprecipitates as these are the major contributor to precipitate strengthening. The agreement, as mentioned above, using the two dissolution methods is quite good.

Another way to determine the amount of nanoprecipitates $(\leq 10 \mathrm{~nm})$ is based on the amount of Mo. ICP analysis of the supernatant indicates that most of the Mo is present in solid solution in the ferrite. The remaining Mo, presented in Table III, is only present in the nanoprecipitates $(\leq 10 \mathrm{~nm})$, as confirmed by TEM EDX analysis (Figures 4, 8, and 9). Therefore, the amount of nanoprecipitates $(\leq 10 \mathrm{~nm})$ can be determined using Eq. [3]. This is based on the chemistry of the nanoprecipitates and the total amount of Mo available for precipitation.

$$
\frac{w t_{\mathrm{Mo}}}{A_{\mathrm{Mo}}}=\frac{w t_{\mathrm{ppt}}}{A_{\mathrm{ppt}}} \times \text { at. } \text { fract }_{\mathrm{Mo}}
$$

where $w t_{\mathrm{Mo}}$ is the total amount (weight) of Mo available for precipitation, which was determined from the total amount of Mo in steel minus that in the supernatant (ICP analysis); $w t_{\mathrm{ppt}}$ is the amount (weight) of nanoprecipitate $(\leq 10 \mathrm{~nm})$ to be determined; $A_{\mathrm{Mo}}$ is the atomic weight of Mo; $A_{\mathrm{ppt}}$ is the molecular weight of the nanoprecipitate $(\leq 10 \mathrm{~nm})$; at. fract $_{\mathrm{Mo}}$ is the atomic fraction of Mo in the nanoprecipitate $(\leq 10 \mathrm{~nm})$, from the nanoprecipitate composition determined from TEM-EDX microanalysis, i.e., 0.28.

Figure 12 shows a comparison of the amount of nanoprecipitates based on Rietveld refinement (via chemical and electrolytic dissolution) and that based on the Mo amount. The amounts of nanoprecipitates $(\leq 10 \mathrm{~nm})$ determined by the three methods are similar.

\section{B. Volume Fraction and Number Density of Nanoprecipitates}

The volume fraction and number density of the nanoprecipitates $(\leq 10 \mathrm{~nm})$ can be determined from their

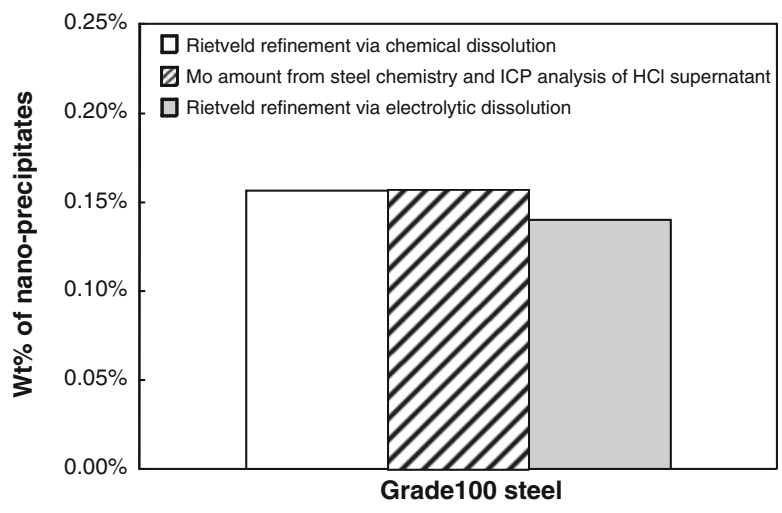

Fig. 12-The amount of nanoprecipitates $(\leq 10 \mathrm{~nm})$ compared with the original mass of the steel.

weight fraction, which has been explained in the previous section. The nanoprecipitates $(\leq 10 \mathrm{~nm})$ have a $\mathrm{NaCl}$-type structure. From the precipitate chemistry, the density of the precipitates can be expressed mathematically as follows ${ }^{[30]}$ :

$$
\rho_{\mathrm{ppt}}=\frac{n A_{\mathrm{ppt}}}{V N_{A}}
$$

where $\rho_{\mathrm{ppt}}$ is the density of the nanoprecipitate, $n$ is the number of formula units in the unit cell $(n=4), A_{p p t}$ is the molecular weight of the precipitate, $V$ is the volume of the unit cell, and $N_{\mathrm{A}}$ is Avogadro's number $\left(6.023 \times 10^{23}\right.$ atoms $\left./ \mathrm{mol}\right)$.

The molecular weight $A_{\text {ppt }}$ can be calculated in the following equation, using $\mathrm{Nb}_{0.48} \mathrm{Mo}_{0.28} \mathrm{Ti}_{0.21} \mathrm{~V}_{0.03} \mathrm{C}$ as an example.

$$
\begin{aligned}
A_{\mathrm{ppt}}= & A_{\mathrm{Nb}} \times 0.48+A_{\mathrm{Mo}} \times 0.28+A_{\mathrm{Ti}} \times 0.21 \\
& +A_{\mathrm{V}} \times 0.03+A_{\mathrm{C}}
\end{aligned}
$$

where $A_{\mathrm{ppt}}$ is the molecular weight of the precipitate, $A_{\mathrm{Nb}}$ is the atomic weight of $\mathrm{Nb}, A_{\mathrm{Mo}}$ is the atomic 
weight of Mo, $A_{\mathrm{Ti}}$ is the atomic weight of $\mathrm{Ti} ; A_{\mathrm{V}}$ is the atomic weight of $\mathrm{V}$, and $A_{\mathrm{C}}$ is the atomic weight of $\mathrm{C}$.

The volume fraction of the nanoprecipitates $(\leq 10 \mathrm{~nm})$ can be calculated as

$$
\operatorname{vol~fraction~}_{\mathrm{ppt}}=\frac{\mathrm{wt} \text { fraction }_{\mathrm{ppt}} \times \rho_{\mathrm{Fe}}}{\rho_{\mathrm{ppt}}}
$$

where vol fraction $_{p p t}$ is the volume fraction of the nanoprecipitates in one unit volume of steel, $\rho_{\mathrm{Fe}}$ is the density of Fe; $\rho_{\mathrm{ppt}}$ is the density of nanoprecipitates, and $\mathrm{wt}$ fraction $_{\mathrm{ppt}}$ is the weight fraction of the nanoprecipitates.

From the preceding TEM precipitate characterization, the nanoprecipitate diameter with the largest number distribution is approximately $4.5 \mathrm{~nm}$. Assuming all the nanoprecipitates $(\leq 10 \mathrm{~nm})$ are spherical and using the $4.5 \mathrm{~nm}$ diameter, the number density of the nanoprecipitates in one unit volume of steel can be calculated based on the total volume of the nanoprecipitates and the volume of a single precipitate, which can be expressed as

$$
\begin{aligned}
\# \text { density } & =\frac{\mathrm{vol}_{\mathrm{ppt}}}{\mathrm{vol}_{\text {single }}} \\
\mathrm{vol}_{\text {single }} & =\frac{4 \pi r^{3}}{3}
\end{aligned}
$$

where vol $_{\mathrm{ppt}}$ is the total volume of nanoprecipitates in 1 $\mu \mathrm{m}^{3}$ of steel, $\mathrm{vol}_{\text {single }}$ is the volume of a single nanoprecipitate; and $r$ is the radius of a nanoprecipitate $(\leq 10 \mathrm{~nm})$ with the largest number distribution determined by DF imaging.

Table X. Weight Fraction, Volume Fraction, and Number Density of Nanoprecipitates

\begin{tabular}{lcc}
\hline Precipitate & $\begin{array}{c}\text { Electrolytic } \\
(10 \text { pct AA })\end{array}$ & $\begin{array}{c}\text { Chemical } \\
(\mathrm{HCl})\end{array}$ \\
\hline Weight fraction (wt pct) & 0.140 & 0.157 \\
Volume fraction (vol pct) & 0.149 & 0.166 \\
$\begin{array}{l}\text { Diameter with the largest } \\
\text { number distribution }(\mathrm{nm})\end{array}$ & 4.5 & 4.5 \\
Number density $\left(\#\right.$ per $\left.\mu \mathrm{m}^{3}\right)$ & 31145 & 34770 \\
\hline
\end{tabular}

The weight fraction, volume fraction and number density of the nanoprecipitates (mainly $\leq 10 \mathrm{~nm}$ ) in Grade100 steel using the two dissolution methods are shown in Table $X$. If the precipitation-strengthening contribution is calculated using Eq. 1, the contribution is in the 185 to $195 \mathrm{MPa}$ range (using the volume percents of 0.140 pct and $0.157 \mathrm{pct}$ ), which represents 27 to 28 pct of the strengthening in the Grade100 steel. ${ }^{[1]}$

\section{Mass balance Comparison between Rietveld and ICP Analysis}

There are two ways to calculate the amounts of $\mathrm{Nb}$, $\mathrm{Ti}$, Mo, and $\mathrm{V}$ that are present in the precipitates, i.e., through Rietveld refinement and ICP analysis of the supernatant. From Rietveld refinement, the relative abundance of different phases in the precipitates is obtained. Based on precipitate chemistries, the total amount of microalloying elements present in the precipitates can be calculated. From an ICP analysis of the supernatant (Table III), the total amount of microalloying elements dissolved in the ferrite matrix can be obtained. The amount of alloying elements present in the precipitates can be determined indirectly by subtracting the amount of alloying elements in the supernatant from the total in the steel. A comparison can then be made between the two methods as shown in Table XI. The agreement generally is good, with the largest difference occurring for $\mathrm{Nb}$. The errors are largest for Rietveld analysis and include errors arising from EDX analysis and XRD pattern profile fitting.

\section{CONCLUSIONS}

Matrix dissolution techniques have been developed to extract and quantify precipitates from a Grade100 microalloyed steel. The following conclusions can be drawn from this investigation:

1. Matrix dissolution is a promising technique to

\begin{tabular}{|c|c|c|}
\hline \multirow[t]{4}{*}{ Wt pet $\mathrm{Nb}$} & total wt pct of $\mathrm{Nb}$ in steel & 0.094 \\
\hline & total wt pct of $\mathrm{Nb}$ in precipitates (Rietveld refinement) & 0.104 \\
\hline & total wt pet of $\mathrm{Nb}$ in precipitates (ICP analysis) & 0.091 \\
\hline & difference* & $-14.0 \mathrm{pct}$ \\
\hline \multirow[t]{4}{*}{ Wt pet $\mathrm{Ti}$} & total wt pet of $\mathrm{Ti}$ in steel & 0.06 \\
\hline & total wt pet of $\mathrm{Ti}$ in precipitates, (Rietveld refinement) & 0.045 \\
\hline & total wt pct of Ti in precipitate (ICP analysis) & 0.046 \\
\hline & difference* & $1.6 \mathrm{pct}$ \\
\hline \multirow[t]{4}{*}{ Wt pct Mo } & total wt pct of Mo in steel & 0.301 \\
\hline & total wt pet of Mo in precipitate (Rietveld refinement) & 0.0439 \\
\hline & total wt pet of Mo in precipitate (ICP analysis) & 0.0437 \\
\hline & difference* & $0.5 \mathrm{pct}$ \\
\hline \multirow[t]{4}{*}{ Wt pet V } & total wt pet of $\mathrm{V}$ in steel & 0.047 \\
\hline & total wt pet of $\mathrm{V}$ in precipitate (Rietveld refinement) & 0.003 \\
\hline & total wt pet of $\mathrm{V}$ in precipitate (ICP analysis) & 0.002 \\
\hline & difference* & $-7.7 \mathrm{pct}$ \\
\hline
\end{tabular}
quantify precipitates in microalloyed steels, providing

Table XI. Mass Balance-Weight Percent of Elements in Steel and in Precipitates for Grade100 Steel

*Difference: (amount from ICP minus amount from Rietveld refinement) divided by amount from ICP analysis. 
quantitative information based on samples that are representative of the steel.

2. Different sized precipitates can be extracted successfully using chemical $(\mathrm{HCl})$ and electrolytic dissolution (10 pct AA, composed of 10 pct acetylacetone, 1 pct tetramethylammonium chloride, and methanol). Chemical dissolution is more efficient for extraction; however, $\mathrm{SiO}_{2}$ comprises a large portion of the residue from chemical dissolution.

3. Matrix dissolution and carbon replicas yield consistent results for precipitate size and chemistry. Carbon replicas validate the matrix dissolution technique.

4. Based on TEM imaging and EDX microanalysis, five groups of precipitates were identified in the Grade100 microalloyed steel in terms of size and composition. Nanoprecipitates $(\leq 10 \mathrm{~nm})$ with an average chemistry corresponding to $\mathrm{Nb}_{0.48} \mathrm{Mo}_{0.28}$ $\mathrm{Ti}_{0.21} \mathrm{~V}_{0.03} \mathrm{C}$ are the most prevalent crystalline phase in the extracted residues using both chemical and electrolytic dissolution methods.

5. Rietveld refinement of XRD patterns can be used successfully to identify and determine the relative amounts of different precipitate phases, making it possible to determine the volume fraction of nanoprecipitates in microalloyed steels.

6. Mass balance of $\mathrm{Nb}, \mathrm{Ti}, \mathrm{Mo}$, and $\mathrm{V}$ is consistent using Rietveld refinement and ICP analysis.

\section{ACKNOWLEDGMENTS}

The authors thank the Natural Sciences and Engineering Research Council (NSERC) of Canada and Evraz Inc., NA for financial support. Provision of experimental materials by Evraz Inc. NA is acknowledged as well.

\section{REFERENCES}

1. D. Bai, M.A. Cooke, J. Asante, and J. Dorricott: Patent US 6,682,613 B2, 2004.

2. S. Wolf: $J O M, 1967$, vol. 19 , pp. 22-28.
3. T. Gladman: The Physical Metallurgy of Microalloyed Steels, The Institute of Materials, London, UK, 1997.

4. K. Poorhaydari-Anaraki: Ph.D. Dissertation, University of Alberta, Alberta, Canada, 2005.

5. A.J. DeArdo: Int. Mater. Rev., 2003, vol. 48 (6), pp. 371-402.

6. S. Akhlaghi and D.G. Ivey: Can. Metall. Q., 2002, vol. 41 (1), pp. 111-19.

7. R. Lagneborg, T. Siwecki, S. Zajac, and B. Hutchinson: Scand. J. Metall., 1999, vol. 28 (5), pp. 186-241.

8. U. Lagerpusch, B. Anczykowski, and E. Nembach: Phil. Mag. A, 2001, vol. 81 (11), pp. 2613-28.

9. M.G. Burke and M.K. Miller: J. Electron Microsc. Tech., 1988, vol. 8, pp. 201-10.

10. K. Stiller and M. Hattestrand: Microsc. Microanal., 2004, vol. 10, pp. 341-48.

11. J. Lu: Ph.D. Dissertation, University of Alberta, Alberta, Canada, 2009.

12. J. Chakraborty, D. Bhattacharjee, and I. Manna: Scripta Mater., 2008, vol. 59, pp. 247-50.

13. J. Chakraborty, D. Bhattacharjee, and I. Manna: Scripta Mater., 2009, vol. 61, pp. 604-07.

14. W. Huang: Metall. Trans. A, 1991, vol. 22A, pp. 1911-20.

15. L.E. Collins, M.J. Godden, and J.D. Boyd: Can. Metall. Q., 1983, vol. 22 (2), pp. 169-79.

16. V.B. Ginzburg: Metallurgical Design of Flat Rolled Steels, Marcel Dekker Inc, New York, NY, 2005.

17. F.G. Wilson and T. Gladman: Int. Mater. Rev., 1988, vol. 33 (5), pp. 211-86.

18. S. Dawson, N.D.G. Mountford, I.D. Sommerville, and A. McLean: Ironmaking Steelmaking, 1988, vol. 15 (10), pp. 54-55.

19. ASTM E194-90, "Standard Test Method for Acid-Insolute Content of Copper and Iron Powders", 1990, pp. 1-2.

20. "Physical Constants of Inorganic Compounds", CRC Handbook of Chemistry and Physics, Knovel, Binghamton, NY, 2004.

21. Y. Yoshida, H. Yoshiko, I. Kanji, and K. Yoshikazu: Kawasaki Steel Giho, 1980, vol. 12 (4), pp. 653-64.

22. H.M. Rietveld: Acta Crystallogr., 1967, vol. 22, pp. 151-52.

23. H.M. Rietveld: J. Appl. Crystallogr., 1969, vol. 2, pp. 65-71.

24. R.J. Hill and C.J. Howard: J. Appl. Crystallogr., 1987, vol. 20, pp. 467-74.

25. S.G. Hong, K.B. Kang, and C.G. Park: Scripta Mater., 2002, vol. 46 (2), pp. 163-68.

26. JCPDS: International Center for Diffraction Data, Newtown Square, PA, 1996, PDF\#00-038-1420, PDF\#00-032-1383, PDF\# 00-038-1155, PDF\#00-039-1425, and PDF\#00-038-1364.

27. E.L. Brown and A.J. DeArdo: Proc. Int. Conf. on the Thermomechanical Processing of Microalloyed Austenite. A.J. DeArdo, G.A. Ratz, and P.J. Wray, eds., AIME, Warrendale, PA, 1982, pp. 319-41.

28. S. Kanazawa, A. Nakashima, K. Okamoto, K. Tanabe, and S. Nakazawa: Trans. Jpn. Inst. Met., 1967, vol. 8 (2), pp. 113-19.

29. W.R. Bandi: Science, 1977, vol. 196 (4286), pp. 136-42.

30. W.D. Callister: Materials Science and Engineering: An Introduction, 5th ed., Wiley, New York, NY, 2000. 